\title{
The role of gas desorption on gas outbursts in underground mining of coal
}

\author{
Sheng Zhi $\cdot$ Derek Elsworth
}

Received: 8 October 2015/ Accepted: 30 March 2016/Published online: 22 April 2016

(C) Springer International Publishing Switzerland 2016

\begin{abstract}
Violent gas outbursts are one of the most severe hazards in underground mining. When outbursts occur, a large amount of coal and gas is suddenly and violently ejected into the roadway and working area with the possibility of serious hazard and injury. Recent studies have shown that the physical behavior responsible for the energetic failure of coal is entirely consistent with coal viewed as a dual porosity-dual permeability-dual stiffness continuum where strength is proportional to effective stresses, and where effective stresses are controlled by both the pore pressure and varying stress field. Gas desorption driven by overstress is highlighted in this study as the key factor responsible for the increase in pore pressure close to the working face, and implicated together with elevated stress level, permeability evolution and drainage conditions in the triggering of outbursts. In this work, we incorporate the likely mass rates of desorption driven by an increase in abutment stress and mediated by permeability evolution to define the rates and distributions of gas pressure changes. The changing pattern of pressure redistribution is identified, and parametric studies are then performed to investigate all the key factors that influence the redistribution of pore pressure with respect to the
\end{abstract}

S. Zhi $(\bowtie) \cdot$ D. Elsworth

Department of Energy and Mineral Engineering, EMS

Energy Institute and G3 Center, Pennsylvania State

University, University Park, PA 16802, USA

e-mail: suz140@psu.edu deformation of the coal seam. Permeability evolution in the overstressed zone is determined by the evolution of porosity, which is attributed to both the change in effective stresses in the abutment and sorptioninduced strain. Considering the weakening effects of desorption-induced pressure increase, energetic failure may be triggered from the pillar as defined by the Mohr-Coulomb failure criterion. According to this analysis, the pore pressure adjacent to the working face may be lowered by drainage in a measurable way to reduce the likelihood of an outburst. This model is capable of predicting the potential risk ahead of the working face during mining and can be adapted to different conditions in terms of varying mechanical factors, coal properties and mining methods.

Keywords Gas outburst - Permeability evolution . Gas desorption · Energetic failure

\section{Introduction}

Gas outbursts in coal mining are defined as the instantaneous and violent ejection of brittle coal, rock and a massive volume of gas, potentially damaging mining machinery, underground support and causing physical injury to personnel. It has been recognized as one of the most severe hazards in underground mining since its early reporting in the 1850 s. More than 30,000 outbursts have occurred historically, of which 
reportedly the most disastrous accident caused 187 deaths in the Piast area of Poland in the Nowa Ruda Colliery, in 1941 (Lama and Bodziony 1998). Nineteen outbursts driven by both of methane and carbon dioxide have been recorded in the Collinsville area, Australia since the first case killing seven men in 1954 (Harvey 2002). Although the frequency of occurrence of outbursts has reduced in recent years with the development of technology and improved mining methods, outbursts remain a dangerous phenomenon in the global underground mining industry.

The mechanism of gas outbursts is known to be a complex integration of stress regime, gas content, permeability evolution and geological structure. As a porous medium, the basic hydraulic characteristics of a coal seam are depicted in Fig. 1 where the mechanical and transport properties may be interlinked through the theory of poroelasticity, viewed either as a single porosity (Biot 1941) or dual porosity (Warren and Root 1963; Elsworth and Bai 1992; Bai et al. 1999) medium. The initial vertical in situ stress state of the coal seam is determined by the weight of the overlying strata. The process of excavation will shed stresses from the excavated area onto the adjacent pillar or rib (Richards 1984). With this elevated effective stress, the adsorbed gas is potentially expelled from the coal matrix as free gas into the pore space (Hol et al. 2011). The aggregation of this free-phase fluid leads to an increased pore pressure in the limited pore volume, while permeability simultaneously declines due to the compaction of the fracture system prior to failure (Somerton et al. 1975; Wang et al. 2012). Due to the abnormal stress distribution and mechanical properties, typical geological structures have been identified to be liable to outbursts such as deformed zones of strike-slip, thrust, reverse, and normal faults and rolls, and slips (Cao et al. 2001; Lama and Bodziony 1998; Shepherd et al. 1981; Wang et al. 2012).

Numerous models have been proposed to explain the mechanism of outburst in the past 160 years. Rarefaction wave theory suggests the impact of tensile waves receives their energy from tensile failure when outbursts are triggered by a variation in stress (Khristianovich 1953). The gas pressure gradient ahead of the working face was proposed to be the trigger of outbursts and studied using a numerical model for gas flow in coal seam by non-linear finite element methods (Paterson 1986). The variation with distance in the abutment stress which drives gas desorption have also been investigated through 2-D numerical modeling for the goaf (Thin et al. 1993) and longwall panel (Mukherjee et al. 1994). Coal seams with low permeability and high desorption rates are noted to be prone to outbursts when mining towards certain geological structures (Williams and Weissman 1995). Notably, existing theories of outbursts may be classified into two broad categories: the pocket model and the dynamic model (Chen et al. 2012). In the pocket model, it is assumed that pockets of gas-rich crushed coal exist in certain area within the coal seam, which trigger an outburst by the rapid liberation of condensed gas. The dynamic model attributes outbursts to tensile/ shear failure, caused by the stress excess to strength of the coal body.

Gas adsorption/desorption, as a factor for the generation of gas outbursts, was initially studied by
Fig. 1 Schematic of a fracture-matrix model for coal. a A coal block with random fractures and gas transport occurring in the fracture and matrix; $\mathbf{b}$ a coal block lacking of horizontal fractures and a simplified 2-D model

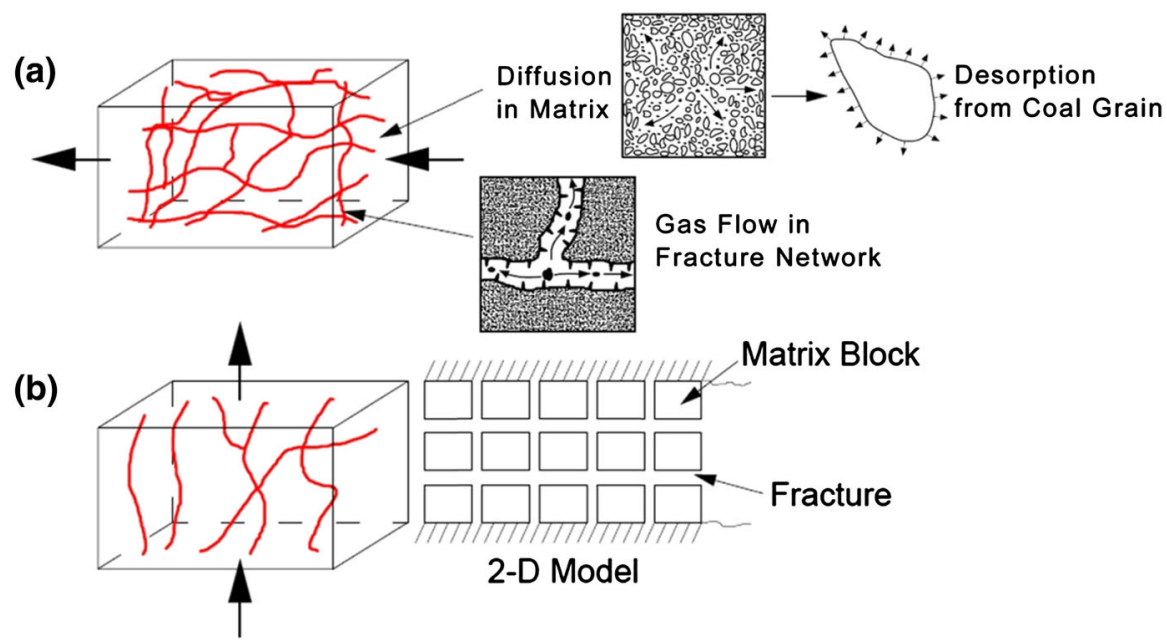


Russian investigators in the 1950s (Lama and Saghafi 2002). Recently, the sorptive behavior of coal has been extensively investigated both theoretically and experimentally, as related to the impact of sorption-induced swelling/shrinkage resulting from $\mathrm{CO}_{2}$ sequestration, enhanced coalbed methane (CBM) production and the prevention of outbursts (An and Cheng 2014; Hol et al. 2011, 2012; Wu et al. 2011). However, few studies relate the contribution of the rapid stress-driven desorption with the redistribution of pore pressure in coal seams during excavation (Wang et al. 2013a).

Recently characterizations are available to define the influence of applied stress on the desorption of gas from coal (Pone et al. 2009; Hol et al. 2011). The sorptive behavior of $\mathrm{CO}_{2}$ is reversible in pre-compacted aggregates of coal grains as a consequence of effective stress, accompanied by reversible deformation. The difference in the amounts of expelled gas between stressed and unstressed condition also demonstrates a reduction in $\mathrm{CO}_{2}$ sorption capacity of coal with respect to the elevated effective stress. Sequential stress desorption experiments were conducted on high volatile bituminous coal have illustrated the near-linear trend of desorption rate and effective stress (Hol et al. 2012).

The permeability of coal is strongly stress-dependent (Harpalani and Schraufnagel 1990; Robertson and Christiansen 2007) with a decrease of 1-3 orders of magnitude in the permeability for changes in effective stress of the order of $10 \mathrm{MPa}$ (Somerton et al. 1975; Durucan and Edwards 1986; Chen et al. 2012). A series of experiments were conducted to measure permeability evolution during the progressive axial compaction, in which the permeabilities fell to minimum ranged from $5 \times 10^{-19}$ to $1 \times 10^{-19} \mathrm{~m}^{2}$ as effective stress increasing (Jasinge et al. 2011; Wang et al. 2013b). In the fragmentation experiments to simulate the energetic failure of coal after rapid degassing, the degree of fragmentation was negatively correlated with the permeability of the coal specimens (Wang et al. 2015). These experimental efforts are fundamental to understand the magnitude of permeability evolution and its influence on the redistribution of pore pressure in coal seam and the generation of gas outburst.

In addition to the effect of mechanical stress, sorptive behavior influences permeability evolution as well. The experiments have shown that sorptioninduced swelling causes a reduction in coal permeability that dominates low gas pressures (Harpalani and Schraufnagel 1990; Jasinge et al. 2012). A series of models (Seidle and Huitt 1995; Palmer and Mansoori 1996; Shi and Durucan 2005; Cui and Bustin 2005; Robertson and Christiansen 2007) based on the Langmuir isotherm have been proposed to investigate sorption-induced strain and its influence on absolute permeability and its anisotropy. The energy balance approach has been used in theoretical models to investigate adsorption-induced swelling, where the change of surface energy induced by adsorption is assumed to be equal to the elastic energy change of the coal (Pan and Connell 2007; Liu and Harpalani 2013). Considering both the mechanical deformation and the sorption-induced strain, the dual porosity-dual permeability-dual stiffness model has been developed to represent permeability evolution and gas transport in coal seams (Liu et al. 2011; Wu et al. 2011).

As a result of these process interactions, lowpermeability coal seams with high pore pressure and low strength are considered to be most prone to energetic outbursts (Lama and Saghafi 2002; Wang et al. 2012). The role gas desorption plays in such energetic failure has been investigated in the laboratory (Wang et al. 2013b, 2015). The weakening effects of high pore pressure on residual shear strength and residual stress are observed in the comparison between overpressured and underpressured coal samples. The degree of fragmentation correlates inversely with coal sample permeability, suggesting that the more energetic failure potentially occurs in low-permeability coal seam with high pore pressure. This may be an important underlying mechanism that controls the stability of coal failure.

Despite abundant studies on gas outbursts in underground mining, the triggering mechanisms remain unresolved. This is due to the difficulty in observing the occurrence of outbursts in situ, and in recreating all phenomenologies and lengthscales in the laboratory. In this study, the role of gas desorption as a mechanism of gas outbursts is investigated by scaling analysis.

\section{Mechanistic model}

In this model the coal is represented as a dual porositydual permeability-dual stiffness continuum, where abutment stresses are applied to the solid medium 
(fracture and matrix). The resulting desorption-induced gas pressures and evolution of permeability are used to follow the path to failure and parametric studies that are used to define key variables.

The analysis is based on the following assumptions:

1. Coal is an homogenous, isotropic and elastic continuum, and the system is isothermal.

2. Gas within coal seams is an ideal gas with constant viscosity and under isothermal conditions.

3. Gas flow through coal body obeys Darcy's law.

\subsection{Governing equation for gas flow}

As an ideal gas, the fluid density is defined as

$\rho_{g}=\frac{p M_{0}}{R T}$

where $\mathrm{p}$ is the absolute gas pressure, $\mathrm{M}_{0}$ represents the molar mass of the fluid, $\mathrm{R}$ is the universal gas constant, $\mathrm{T}$ is the absolute temperature of the gas.

Since the overstress triggers changes in both pore pressure and volumetric strain, the expression for change of fluid mass is written as

$\Delta m_{f}=\frac{M_{0}}{R T Z}(\phi \Delta p+p \Delta \phi)$

where $\phi$ is the porosity of the coal, $\Delta$ represents a finite derivative. Assuming that fluid flow obeys Darcy's law then

$q=-\frac{k}{\mu} \nabla p$

where $\mathrm{k}$ is permeability, $\mu$ is the dynamic viscosity of the fluid, and $\nabla \mathrm{p}$ is the pressure gradient.

Hence, adding a gas source $\mathrm{Q}_{\mathrm{m}}$ then yields

$\frac{\partial m_{f}}{\partial t}+\nabla\left(q \cdot \rho_{g}\right)=Q_{m}$

as a time-dependent equation based on mass balance for gas flow in the porous medium.

\subsection{Governing equation for coal deformation}

The stress-strain relations for an isotropic linear material are expressed as:

$\varepsilon_{i j}=\frac{1+v}{E} \sigma_{i j}-\frac{v}{\mathrm{E}} \delta_{\mathrm{ij}}\left(\sigma_{11}+\sigma_{22}+\sigma_{33}\right)$ where $\mathrm{E}$ and $v$ are Young's modulus and Poisson ratio, respectively. $\delta_{\mathrm{ij}}$ is the Kronecker delta, defined so that $\delta_{\mathrm{ij}}=1$ if $\mathrm{i}=\mathrm{j}$, and $\delta_{\mathrm{ij}}=0$ otherwise.

The bulk modulus $\mathrm{K}$ is defined by writing

$\varepsilon_{v}=-\frac{\Delta \mathrm{V}}{\mathrm{V}}=\frac{\left(\sigma_{11}+\sigma_{22}+\sigma_{33}\right)}{3 \mathrm{~K}}$

where $\mathrm{K}$ is the bulk modulus.

The stress and strain relationship with the consideration of pore pressure $\mathrm{p}$ and the Biot coefficient $\alpha=\mathrm{K} / \mathrm{K}_{\mathrm{s}}$ is

$\sigma_{\mathrm{ij}}=2 \mathrm{G} \varepsilon_{\mathrm{ij}}+\left(\mathrm{K}-\frac{2}{3} \mathrm{G}\right) \delta_{\mathrm{ij}}\left(\varepsilon_{11}+\varepsilon_{22}+\varepsilon_{33}\right)+\alpha \delta_{\mathrm{ij}} \mathrm{p}$

From its inverse relation, the constitutive stressstrain relation for the deforming coal seam is shown as $\varepsilon_{\mathrm{ij}}=\frac{1}{2 \mathrm{G}} \sigma_{\mathrm{ij}}-\left(\frac{1}{6 \mathrm{G}}-\frac{1}{9 \mathrm{~K}}\right) \sigma_{\mathrm{kk}} \delta_{\mathrm{ij}}-\frac{\alpha}{3 \mathrm{~K}} \mathrm{p} \delta_{\mathrm{ij}}+\frac{\varepsilon_{\mathrm{s}}}{3} \delta_{\mathrm{ij}}$

where is the sorption-induced strain. By incorporating the sorption-induced strain into this stress-strain relationship, the volumetric strain is expressed as (shrinkage is considered as positive)

$$
\begin{aligned}
\mathrm{d} \varepsilon_{\mathrm{v}} & =-\frac{\mathrm{dV}}{\mathrm{V}}=\frac{1}{\mathrm{~K}} \mathrm{~d} \bar{\sigma}-\left(\frac{1}{\mathrm{~K}}-\frac{1}{\mathrm{~K}_{\mathrm{s}}}\right) \mathrm{dp}+\varepsilon_{\mathrm{s}} \\
& =\frac{1}{\mathrm{~K}}(\mathrm{~d} \bar{\sigma}-\alpha \mathrm{dp})+\varepsilon_{\mathrm{s}}
\end{aligned}
$$

Equation (9) defines the full suite of relationships to describe the net strain between the mechanical compression and the sorptive strain.

\subsection{Governing equation for permeability evolution}

An isothermal Langmuir-type equation is used to describe the sorption-induced volumetric strain as

$\varepsilon_{\mathrm{s}}=\varepsilon_{\mathrm{L}} \frac{\mathrm{p}}{\mathrm{p}_{\mathrm{Ls}}+\mathrm{p}}$

where the Langmuir volumetric strain, $\varepsilon_{\mathrm{L}}$, represents the volumetric strain at infinite pore pressure and the Langmuir pressure constant, $\mathrm{p}_{\mathrm{Ls}}$, represents the pore pressure at one-half of the Langmuir volumetric strain.

An isothermal Langmuir-type equation for sorption is defined as 
$\mathrm{V}=\mathrm{V}_{\mathrm{L}} \frac{\mathrm{p}}{\mathrm{p}_{\mathrm{Lv}}+\mathrm{p}}$

where the Langmuir volume constant, $\mathrm{V}_{\mathrm{L}}$, represents the adsorption volume of gas at infinite pore pressure and the Langmuir pressure constant, $\mathrm{p}_{\mathrm{Lv}}$, represents the pore pressure at one-half of the Langmuir volume.

The sorption-induced strain $\Delta \varepsilon_{\mathrm{s}}$ due to the pressure change from $\mathrm{p}_{1}$ to $\mathrm{p}_{2}$ can be written as

$\Delta \mathrm{V}=\mathrm{V}_{2}-\mathrm{V}_{1}=\mathrm{V}_{\mathrm{L}}\left(\frac{\mathrm{p}_{2}}{\mathrm{p}_{\mathrm{Lv}}+\mathrm{p}_{2}}-\frac{\mathrm{p}_{1}}{\mathrm{p}_{\mathrm{Lv}}+\mathrm{p}_{1}}\right)$

rearranging Eq. (19) yields

$\mathrm{p}_{2}=\frac{\left(\frac{\mathrm{p}_{1}}{\mathrm{p}_{\mathrm{Lv}}+\mathrm{p}_{1}}+\frac{\Delta \mathrm{V}}{\mathrm{V}_{\mathrm{L}}}\right) \mathrm{P}_{\mathrm{L}}}{\left(\frac{\mathrm{p}_{\mathrm{Lv}}}{\mathrm{p}_{\mathrm{Lv}}+\mathrm{p}_{1}}-\frac{\Delta \mathrm{V}}{\mathrm{V}_{\mathrm{L}}}\right)}$

and subtracting $\mathrm{p}_{2}$ recovers the resulting swelling strain as

$\Delta \varepsilon_{\mathrm{s}}=\varepsilon_{\mathrm{L}} \frac{\mathrm{p}_{\mathrm{Ls}}\left(\mathrm{p}_{2}-\mathrm{p}_{1}\right)}{\left(\mathrm{p}_{\mathrm{Ls}}+\mathrm{p}_{2}\right)\left(\mathrm{p}_{\mathrm{Ls}}+\mathrm{p}_{1}\right)}$

The coupling of Eqs. (12) and (14) defines the relationship between the expelled gas volume $\Delta \mathrm{V}$ and the sorptive strain $\Delta \varepsilon_{\mathrm{s}}$ based on the wildly applied Langmuir model.

A dual porosity-dual permeability model is implemented by introducing porosities for fracture and matrix respectively, whose basic scheme is shown as Fig. 1. The initial fracture porosity $\phi_{\mathrm{f} 0}$ is defined as $3 \mathrm{~b} / \mathrm{s}$, where $\mathrm{b}$ is the fracture aperture and $\mathrm{s}$ is the space between two parallel fractures. The initial matrix porosity $\phi_{\mathrm{m} 0}$ is equivalent to the ratio between the matrix void volume and total bulk volume. The total porosity $\phi$ is the result of addition of these two types of porosities.

In this study, we assume that the normal closure and opening of fractures are elastic and fully reversible, which are the predominant causes for changes in porosity. Considering that the coal matrix is homogeneous and isotropic, sorptive strain is isotropic. Based on these assumptions, the change in fracture porosity can be expressed as

$\Delta \mathrm{b}=(\mathrm{s}+\mathrm{b}) \frac{\Delta \sigma_{\mathrm{ff}}}{\mathrm{E}}-s \frac{\Delta \sigma_{\mathrm{eff}}}{\mathrm{E}_{\mathrm{m}}}+\mathrm{s} \frac{\Delta \varepsilon_{\mathrm{s}}}{3}$

Because the mechanical strain in the fracture is $\Delta \varepsilon_{\mathrm{f}}=\Delta \mathrm{b} / \mathrm{b}$ and the change in $\Delta \phi_{\mathrm{f}}=\phi_{\mathrm{f} 0} \cdot \Delta \varepsilon_{\mathrm{f}}$,
$\Delta \varepsilon_{\mathrm{f}}=\left[\frac{\mathrm{s}}{\mathrm{b}}\left(1-\mathrm{R}_{\mathrm{m}}\right)+1\right] \Delta \varepsilon_{\mathrm{eff}}+\frac{\mathrm{s}}{\mathrm{b}} \frac{\Delta \varepsilon_{\mathrm{s}}}{3}$

$\Delta \phi_{\mathrm{f}}=3 \Delta \varepsilon_{\mathrm{eff}}\left(1-\mathrm{R}_{\mathrm{m}}\right)+\Delta \varepsilon_{\mathrm{s}}$

where $R_{m}$ is the elastic modulus reduction ratio, equivalent to $E / E_{m}$. $E$ and $E_{m}$ are Young's modulus for the coal body and coal matrix, respectively. Similarly, the change in matrix porosity can be expressed as

$\Delta \phi_{\mathrm{m}}=\frac{\Delta \sigma_{\mathrm{eff}}}{\mathrm{E}_{\mathrm{m}}}=\frac{\Delta \sigma_{\mathrm{eff}}}{\mathrm{E}} \frac{\mathrm{E}}{\mathrm{E}_{\mathrm{m}}}=\Delta \varepsilon_{\mathrm{eff}} \cdot \mathrm{R}_{\mathrm{m}}$

Considering the cubic relation between porosity and permeability

$\frac{\mathrm{k}}{\mathrm{k}_{0}}=\left(\frac{\phi}{\phi_{0}}\right)^{3}$

the change of fracture permeability $\mathrm{k}_{\mathrm{f}}$ can be written as

$\frac{\mathrm{k}_{\mathrm{f}}}{\mathrm{k}_{\mathrm{f} 0}}=\left(1+\frac{\Delta \phi_{\mathrm{f}}}{\phi_{\mathrm{f} 0}}\right)^{3}$

Substituting Eqs. (9), (14) and (17) into (20) then yields

$\frac{\mathrm{k}_{\mathrm{f}}}{\mathrm{k}_{\mathrm{f} 0}}=\left(1+\frac{\frac{3}{\mathrm{~K}}(\mathrm{~d} \bar{\sigma}-\alpha \mathrm{dp})\left(1-\mathrm{R}_{\mathrm{m}}\right)+\varepsilon_{\mathrm{L}} \frac{\mathrm{p}_{\mathrm{Ls}}\left(\mathrm{p}_{2}-\mathrm{p}_{1}\right)}{\left(\mathrm{p}_{\mathrm{Ls}}+\mathrm{p}_{2}\right)\left(\mathrm{p}_{\mathrm{Ls}}+\mathrm{p}_{1}\right)}}{\phi_{\mathrm{f} 0}}\right)^{3}$

Similarly, change in matrix permeability $\mathrm{k}_{\mathrm{m}}$ can be written as

$\frac{\mathrm{k}_{\mathrm{m}}}{\mathrm{k}_{\mathrm{m} 0}}=\left(1+\frac{\Delta \varepsilon_{\mathrm{eff}} \cdot \mathrm{R}_{\mathrm{m}}}{\phi_{\mathrm{f} 0}}\right)^{3}=\left(1+\frac{\frac{1}{\mathrm{~K}}(\mathrm{~d} \bar{\sigma}-\alpha \mathrm{dp}) \mathrm{R}_{\mathrm{m}}}{\phi_{\mathrm{f} 0}}\right)^{3}$

Therefore, combining the changes in the two systems, the resultant change in permeability can be expressed as (Van Golf-Racht 1982; Liu et al. 2011)

$\mathrm{k}=\mathrm{k}_{\mathrm{f}}+\mathrm{k}_{\mathrm{m}}$

Substituting Eqs. (21), (22) into (30) gives

$$
\begin{aligned}
\frac{\mathrm{k}}{\mathrm{k}_{0}} & =\frac{\mathrm{k}_{\mathrm{f} 0}}{\mathrm{k}_{\mathrm{f} 0}+\mathrm{k}_{\mathrm{m} 0}} \\
& \left(1+\frac{\left.\frac{3}{\mathrm{~K}}(\mathrm{~d} \bar{\sigma}-\alpha \mathrm{dp})\left(1-\mathrm{R}_{\mathrm{m}}\right)+\varepsilon_{\mathrm{L}} \frac{\mathrm{p}_{\mathrm{Ls}}\left(\mathrm{p}_{2}-\mathrm{p}_{1}\right)}{\left(\mathrm{p}_{\mathrm{Ls}}+\mathrm{p}_{2}\right)\left(\mathrm{p}_{\mathrm{Ls}}+\mathrm{p}_{1}\right)}\right)^{3}}{\phi_{\mathrm{f} 0}}\right. \\
& +\frac{\mathrm{k}_{\mathrm{m} 0}}{\mathrm{k}_{\mathrm{f} 0}+\mathrm{k}_{\mathrm{m} 0}}\left(1+\frac{\frac{1}{\mathrm{~K}}(\mathrm{~d} \bar{\sigma}-\alpha \mathrm{dp}) \mathrm{R}_{\mathrm{m}}}{\phi_{\mathrm{f} 0}}\right)^{3}
\end{aligned}
$$


Equation (24) represents the constitutive relationship between the post- and pre-excavation permeabilities due to the combination of mechanical strain and sorption-induced swelling/shrinkage.

\section{Numerical solution}

The above governing equations are incorporated into a modified model, which is designed to represent a coal seam undergoing mining. This model focuses on the redistribution of pore pressure, alteration in effective stress, evolution of porosity and permeability and their relationships coupled with the initiation of outbursts. Due to the diversity of conditions underground and the difficulty in observing, the occurrence of outbursts, these correlated properties are used for a parametric evaluation of their importance in triggering outbursts. The coupled equations are implemented in and solved using COMSOL Multiphysics.

\subsection{Model description}

As a result of the mining-induced change in stress, there exist four different zones inboard from the pillar. There are the front abutment zone, crushed zone, stress-relief zone and the recompaction zone (Durucan and Edwards 1986). Similarly, based on the distribution of pore pressure, the coal seam is divided into a zone of coal gas abundance zone, a low permeability zone and a pristine zone (An and Cheng 2014). As shown in Fig. 2, the model in this study consists of four parts: a fractured zone, an overstressed zone, an undisturbed (in situ) zone and a goaf zone. The basic parameters in this model are partially listed in Table 1, with temperature $\mathrm{T}$ considered constant due to underground ventilation.

1. The fractured zone has an initial permeability of $1000 \mathrm{k}_{\mathrm{m}}$ and its abutment stress decreases rapidly until reaching the working face.

2. The key component in our analysis, the overstressed zone has an initial permeability determined by $\mathrm{k}_{\mathrm{f}} / \mathrm{k}_{\mathrm{m}}$, subject to a linearly increasing abutment stress.

3. The pristine in situ zone has the same initial permeability as the overstressed zone and is subject to the initial state of stress.

4. With the roof and the upper strata collapsing, the overburden stress is re-established in the goaf zone. A gas accumulation may occur within the

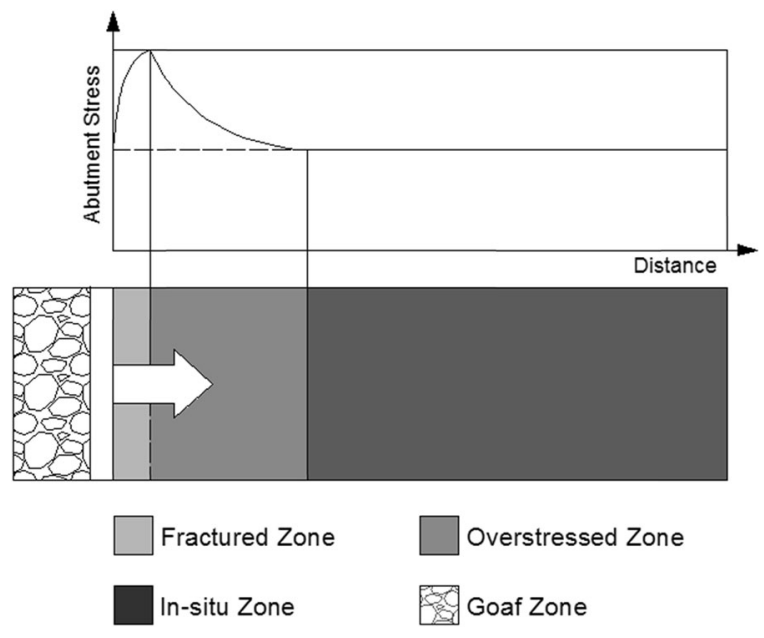

Fig. 2 Three zones of the coal seam model: (1) fractured zone with high permeability; (2) overstressed zone with gas desorption and the changing abutment stress; (3) in-situ zone with the virgin permeability and the initial stress condition

caved waste after a period of time, but this consideration is beyond the range of this study.

In a porous medium, permeability is the key feature describing the capacity of fluid to migrate through it. Typically, in a dual permeability fracture-matrix system, the matrix permeability $\mathrm{k}_{\mathrm{m}}$ is very low and the fracture permeability $k_{f}$ varies as a result of the fracture orientations and the dilation of those fractures (Perera et al. 2013). Permeability is evaluated by the change in porosity, which is stress-dependent. Porosity plays a pivotal role in transferring the impact of mechanical stress to permeability. On the one hand, gas flow is obstructed since the permeability decreases due to the change in porosity. On the other hand, the reduction in porosity induced by effective stress results in less pore space leading to a rise in pore pressure. The boundary condition at the longwall mining face is assumed to atmospheric pressure, where the coalbed methane dissipates naturally through coal body into the roadways and working-face area due to the pressure gradient following the Darcy's law.

The abutment stresses, including the vertical and horizontal abutment stress, are the resultant of the initial stress field and mining-induced stress field. The increment in abutment stresses ahead of working face drives gas desorption, resulting in the accumulation of free fluid with elevated pressure. The competition between gas dissipation and gas accumulation 
Table 1 Modeling parameters for the numerical simulation

\begin{tabular}{ll}
\hline Parameter & Value \\
\hline Young's modulus of coal $(\mathrm{E}, \mathrm{GPa})$ & 2.71 \\
Poisson's ratio of coal $(v)$ & 0.34 \\
Density of coal $\left(\rho_{\mathrm{c}}, \mathrm{kg} / \mathrm{m}^{3}\right)$ & 1250 \\
Gas dynamic viscosity $(\mu, \mathrm{Pa} \mathrm{s})$ & $1.84 \mathrm{E}-05$ \\
Temperature $(\mathrm{T}, \mathrm{K})$ & 313.14 \\
$\mathrm{CH}_{4}$ desorption rate for unit volume of coal $(\mathrm{kg} / \mathrm{MPa})$ & 0.03156 \\
$\mathrm{CH}_{4}$ Langmuir volume constant $\left(\mathrm{V}_{\mathrm{L}}, \mathrm{m}^{3} / \mathrm{kg}\right)$ & 0.0191 \\
$\mathrm{CH}_{4}$ Langmuir volumetric strain constant $\left(\varepsilon_{\mathrm{L}}\right)$ & 0.0128 \\
$\mathrm{CH}_{4}$ Langmuir pressure constant $\left(\mathrm{P}_{\mathrm{Lv}}, \mathrm{MPa}\right)$ & 2.47 \\
$\mathrm{CH}_{4}$ Langmuir pressure constant $\left(\mathrm{P}_{\mathrm{Ls}}, \mathrm{MPa}\right)$ & 4.15 \\
Initial matrix porosity $\left(\phi_{\mathrm{m}}\right)$ & 0.03 \\
Initial matrix permeability $\left(\mathrm{k}_{\mathrm{m}}, \mathrm{m}^{2}\right)$ & $5.00 \mathrm{E}-19$ \\
\hline
\end{tabular}

principally determines the evolution of the gas pressure. Furthermore, as mentioned above, the increasing abutment stress results in compressive strain, lowers the porosity of the coal seam and consequently decreases the permeability. When gas is desorbed from the matrix, the sorption-induced strain is one part component of the net volumetric strain. If pre-drainage is performed, the initial pressure near the working face will be reduced. Therefore, as shown in Fig. 3, the change in pore pressure within coal seam near the working face is influenced by not only gas desorption, but also gas dissipation, volumetric strain, drainage and their interactions.

Figure 4 shows the results of permeability evolution using the current model in comparison with the experimental data obtained from the gas sorption experiments (Robertson and Christiansen 2007; Harpalani and Schraufnagel 1990). The $\mathrm{CO}_{2}$ and $\mathrm{CH}_{4}$ sorption experiments were conducted with the varying effective stress to investigate the relationship between the sorption-induced strain and mechanical compaction, while $\mathrm{N}_{2}$ and Helium were used to exclude the sorptive effect as a control group. The experimental results shows that the permeability starts to decrease at the onset of pressure increasing due to the sorption-induced swelling but increases at higher pore pressure as a result of a less effective confining stress attributing to the opened fractures. The properties of the coal sample are obtained from a prior study (Liu et al. 2011), with undefined parameters as $k_{\mathrm{f}} / \mathrm{k}_{\mathrm{m}}$ and $R_{m}$ estimated within reasonable ranges (see Fig. 4). The matches between experiment and model show that our modeling results match the experimental data reasonably well, proving the validity of this model depicting the sorptive behavior of coal under a varying effective stress condition.

\subsection{Parametric study}

As discussed previously, stress state, desorption rate and permeability evolution all influence the evolution of pressure distribution during coal excavation. The most important parameters that influence the occurrence of outbursts can be grouped into three categories: (1) mechanical factors, including depth of coal seam, stress concentration factor and elastic modulus reduction ratio; (2) coal properties, including permeability ratio, desorption rate and fracture porosity; and (3) the impacts of mining method, including the length of the overstressed zone, residual initial pressure ratio and mining rate. A comprehensive parametric study is conducted using the controlled variable method. Complex geologic structure is excluded in this study, but its influence is manifest in other key factors. All these parameters are listed in Table 2.

\subsubsection{Depth of coal seam (D)}

This is one of the most important factors as it determines the in situ stress field including an influence on the initial vertical and horizontal stresses. The initial vertical stress is estimated from the overburden depth. Prior studies interpreted that the horizontal stress is high at shallow depth but decreases with depth increasing (Sheorey 1994). The horizontal stress/vertical stress ratio is set to unity for 


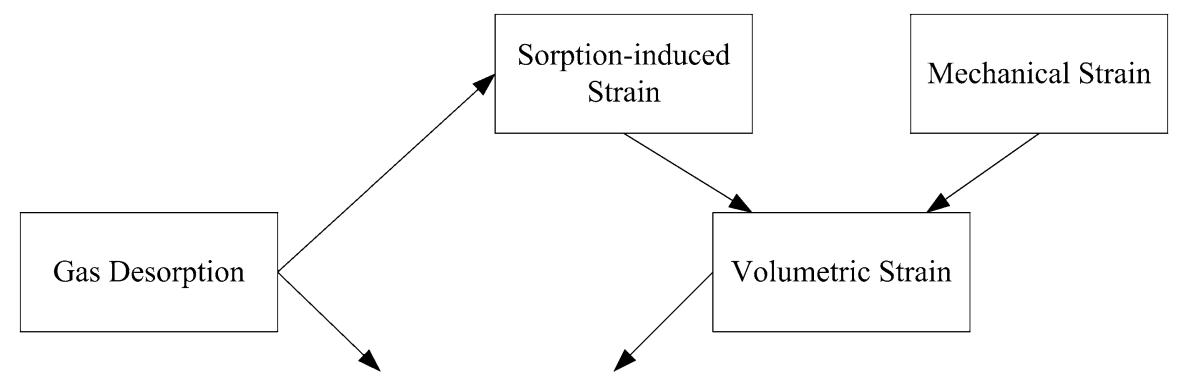

\section{Change in Pore Pressure}

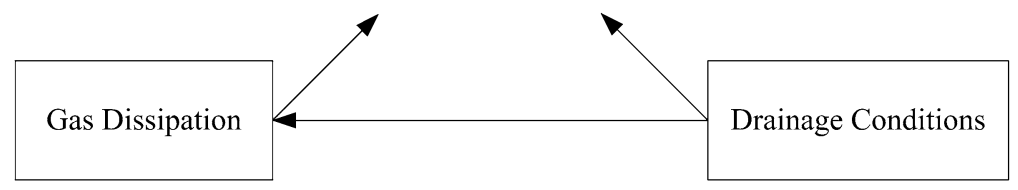

Fig. 3 Schematic of factors influencing the change in pore pressure within a pillar. The evolution of pore pressure within a coal seam is determined by the competition between the desorption-induced accumulation of free gas and its dissipation due to the evolution (increase) in permeability. The mechanical strain occurring in coal seams reduces the volume of the pore space, while the sorption-induced shrinkage partly compensates for this reduction. Drainage conditions, like methane extraction and hydraulic fracturing, also influence the fluctuation of pore pressure
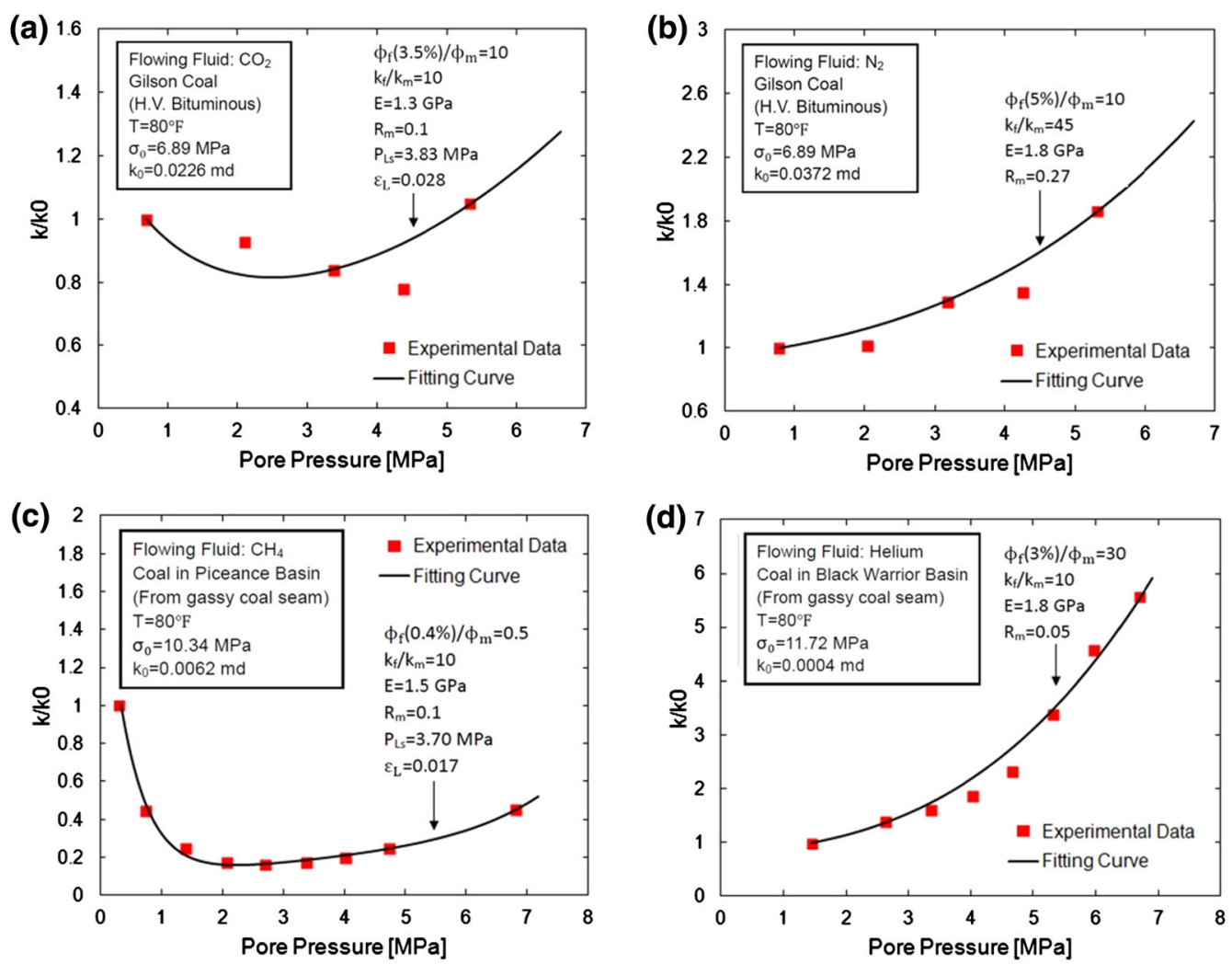

Fig. 4 Comparisons of modeling results with experimental data of different gases $\left(\mathrm{CO}_{2}, \mathrm{~N}_{2}, \mathrm{CH}_{4}, \mathrm{He}\right)$ under varied confining condition 
Table 2 Variable magnitude ranges used in the parametric studies
The values denoted with an $*$ are used as default values unless otherwise noted

\begin{tabular}{ll}
\hline Parameter & Value \\
\hline Depth $\mathrm{D}(\mathrm{m})$ & $-200,-400,-600^{*},-800,-1000$ \\
Elastic modulus reduction ratio $\mathrm{R}_{\mathrm{m}}(-)$ & $0.1,0.3,0.5^{*}, 0.7,0.9$ \\
Stress concentration factor $\mathrm{C}(-)$ & $1^{*}, 1.25,1.5,1.75$ \\
Fracture porosity $\phi_{\mathrm{f}}(-)$ & $0.6,0.8,1.0^{*}, 1.2,1.4$ \\
Ratio of fracture and matrix permeability $\mathrm{k}_{\mathrm{f}} / \mathrm{k}_{\mathrm{m}}(-)$ & $0.01,0.015^{*}, 0.02,0.03,0.05$ \\
Ratio of desorption rate $\mathrm{R}_{\mathrm{de}} / \mathrm{R}_{\mathrm{de} 0}(-)$ & $1,10^{*}, 100,1000$ \\
Length of overstressed zone $\mathrm{L}_{\mathrm{oz}}(\mathrm{m})$ & $60,80,100^{*}, 120$ \\
Initial pressure reduction ratio $\mathrm{R}_{\mathrm{i}}(-)$ & $0.4,0.6^{*}, 0.8,1.0$ \\
Mining rate $\mathrm{M}(\mathrm{m} /$ day) & $5,10^{*}, 15,20$ \\
\hline
\end{tabular}

simplicity in this study. The initial pore pressure within the coal seam is controlled by the underground water level, which is regarded as equivalent of static water column at the same height.

\subsubsection{Elasitic modulus reduction ratio $\left(R_{m}\right)$}

Considering the dual stiffnesses of the dual porosity medium, different mechanical responses exist in both fracture and matrix. The elastic modulus reduction ratio is defined as $\mathrm{E} / \mathrm{E}_{\mathrm{m}}$, where $\mathrm{E}$ is the Young's modulus for the dry coal aggregate and $E_{m}$ is the Young's modulus for the coal matrix. The variation in $R_{m}$ represents different contributions of the fracture and matrix to the volumetric strain. If $E_{m} \gg E, R_{m}$ is close to zero, which means the deformation is predominantly in fractures and cracks. Otherwise, when $R_{m}$ approaches 1 , the coal body can be considered as unfractured and the volumetric strain is determined by the matrix modulus (Liu et al. 2011).

\subsubsection{Stress concentration factor $(C)$}

During mining the vertical abutment stress is concentrated close to the working face. This phenomenon has been widely observed both in situ and in computational studies. Specifically, this vertical abutment stress gradually increases from the far field and reach a maximum close to the working face, whereafter it then reduce to null. The peak value can be estimated as of the order of twice the initial stress. A stress concentration factor $\mathrm{C}$ is defined as the ratio between the excess stress of peak abutment stress and the initial gravitational stress, which is widely suggested to be unity when undergoing periodic roof weighting (Thin et al. 1993). This ratio can also be influenced by the geological conditions and by mining methods. In an isolated panel, for instance, the stress concentration factor can be higher when zones of influence from adjacent panels overlap. The distance from the working face to where abutment stress reaches its peak is predicted to be 1-5 m (Richards 1984). Meanwhile, the change in horizontal abutment stress is relatively small compared with the vertical stress. Approximately 2-10\% increments in the horizontal abutment stress is inferred from field monitoring (Zhang et al. 2013) and numerical solution (Yang et al. 2011), respectively. In this study, an increment of $10 \%$ in the maximum of the horizontal stress is adopted. Figure 5 shows a typical distribution of the abutment stress for a depth of $\mathrm{D}=-600 \mathrm{~m}$ and $\mathrm{C}=1$.

\subsubsection{Fracture porosity $\left(\phi_{\mathrm{f}}\right)$}

$\phi_{\mathrm{f}}$ is defined as the fracture void volume/the total bulk volume and $\phi_{\mathrm{m}}$ is defined as the matrix void volume/ the total bulk volume. The conception of double porosities plays a significant role in the estimation of permeability evolution and gas transport in coal. The virgin value of $\phi_{\mathrm{f}}$ is modulated by the quantity and the orientation of fractures existing within the coal seam. However, its variation during excavation is not only dependent on mechanical strain, but also influenced by sorption-induced swelling/shrinkage. Generally, $\phi_{\mathrm{m}}$ is less sensitive to changes in stress than $\phi_{\mathrm{f}}$.

\subsubsection{Permeability ratio $\left(k_{f} k_{m}\right)$}

Typical in situ matix permeabilities are of the order of $5 \times 10^{-19} \mathrm{~m}^{2}$ (Wang et al. 2013a) and vary little. Conversely, fracture permeabilities vary significantly 
Fig. 5 Mining-induced changes in vertical stress and horizontal stress at a depth of $\mathrm{D}=-600 \mathrm{~m}$ and $\mathrm{C}=1$. The vertical stress is controlled by a stress concentration factor $(\mathrm{C})$, which is generally considered as unity. An increment of $10 \%$ in the maximum of the horizontal stress is adopted in this study

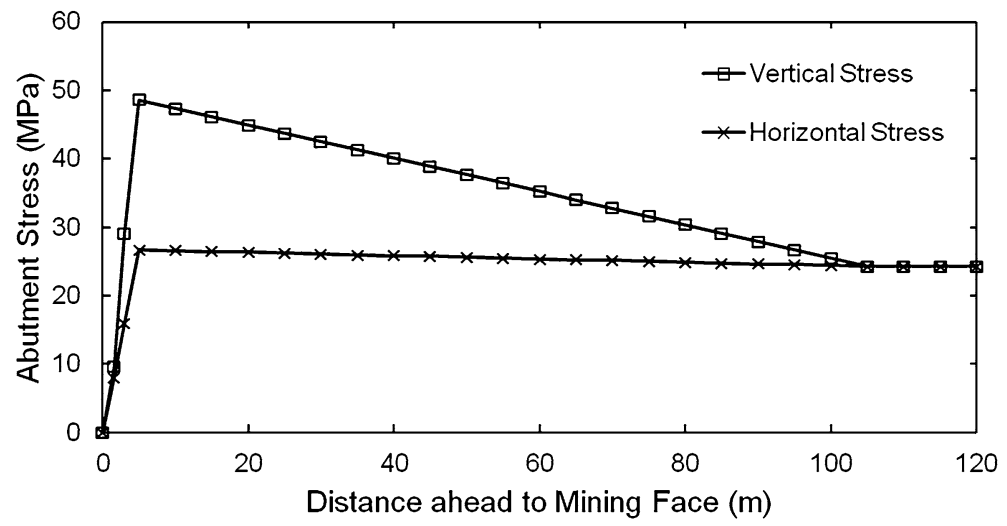

as a result of fracture orientation and stress dependent aperture. The longitudinal fracture permeability is determined by permeability ratio $\mathrm{k}_{\mathrm{f}} / \mathrm{k}_{\mathrm{m}}$ with the matrix permeability determined from the bulk deformation of the rock mass.

\subsubsection{Desorption rate $\left(R_{d e}\right)$}

$\mathrm{CO}_{2}$ desorption results in a nearly linear relationship between the expelled mass of $\mathrm{CO}_{2}$ and high effective stress (Hol et al. 2012). However, the predominant composition of gas in coalbeds is methane. Adsorption experiments of different gases on coal sample from wells (Joppe-1) suggests that the sorption capacity of methane is $\sim 0.6$ times of that of $\mathrm{CO}_{2}$ at a pressure of $4 \mathrm{MPa}$ and temperature of $40{ }^{\circ} \mathrm{C}$ (Krooss et al. 2002). Besides the types of gas, the sorption capacity is also influenced by temperature, moisture content, volatility and other physical properties of coal. These variation in typical sorption isotherm can be described by experimentally measured Langmuir parameters (Harpalani and Mitra 2010), which are adopted in this study. Thus, by scaling, the desorption rate of methane is considered to be $1.97 \mathrm{~mol} / \mathrm{MPa}$ for a unit volume of coal $\left(1 \mathrm{~m}^{3}\right)$.

\subsubsection{Length of over-stressed zone $\left(L_{o z}\right)$}

The form of the abutment stresses is scaled by the length of the fractured zone $\mathrm{L}_{\mathrm{fz}}$ and length of the overstressed zone $\mathrm{L}_{\mathrm{oz}}$. $\mathrm{L}_{\mathrm{fz}}$ is usually estimated as a small magnitude $(\sim 5 \mathrm{~m}$ in the proposed model), whereas the decay length $\mathrm{L}_{\mathrm{oz}}$ varies considerably. $\mathrm{L}_{\mathrm{oz}}$ is the needed distance for the abutment stress to return to the original overburden stress from its maximum and has a strong influence on the dynamic distribution of fluid pressure as a result of gas desorption. Earlier studies suggested that $\mathrm{L}_{\mathrm{oz}}$ is not only related to the depth where the coal seam is located, but also seam thickness, height of caving and mechanical properties of the roof (Thin et al. 1993).

\subsubsection{Residual initial pressure ratio $\left(R_{i}\right)$}

In reality, the initial pore pressure is usually less than expected due to the drawdown condition as gas dissipates. Residual initial pressure ratio $R_{i}$ is defined as the ratio between the initial equilibrium pore pressure within the pillar prepared for mining and the initial hydrostatic pressure. Before the drivage of prepared roadway starts, gas has been dissipating into the adjacent excavated space connected to the atmospheric pressure via ventilation equipment. Meanwhile, the dispersed gas is partially compensated by the intact coal seam connected with this area as the whole seam is considered as an infinite gas reservoir. $\mathrm{Ri}$ is also corresponded to the effect of the predrainage. The parameter determines the initial pressure level and the boundary condition in the model.

\subsubsection{Mining rate $(M)$}

For longwall mining considered here, mining rate is defined as the distance that the working face advances per day without intermission. For a static location, if the abutment stress is considered uniform to migrate at the mining advance rate, this determines the rate of stress increase within the pillar. Therefore the desorption rate will scale linearly due to the change of effective stress. 


\section{Results and discussion}

With a model and its dependencies defined, we apply it to examine the anticipated pore pressure distribution as a result of mining. Specifically we examine the impacts of initial stress states and their variation, material properties of permeability evolution and the influence of mining methods. We examine pore pressure distribution and its peak magnitudes and compare these with dimensionless controlling values. We then used these characterizations to explore the stability of the pillar against failure.

\subsection{Gas pressure profile at the face}

Figure 6 shows the results of the numerical simulation for the redistribution of pore pressure induced by the mechanical loading in coal seam during mining works. It is evident that the distribution of pore pressure is strongly controlled by the depth of the coal seam. A greater peak pore pressure results with an increasing in depth and overburden stress, which is considered as hazardous ahead of the working face. This increasing pattern of pore pressure in overstressed zone gradually diminishes in the shallower underground mines. The elastic modulus reduction ratio $R_{m}$ has a strong influence on permeability alteration, and subsequently influences the distribution of pore pressure. Its influence is clear for the highpermeability case to the large contrast in the two types of permeabilities. Peak pore pressure increases with a larger stress concentration factor $\mathrm{C}$, shown in Fig. 6c.

The results for the different pore pressure redistribution induced by the changes in coal properties are shown in Fig. 7. A larger fracture porosity $\phi_{\mathrm{f}}$ results in a reduction in pore pressure due to the larger receptor volume for the desorbed gas in the coal. As the fracture permeability $\mathrm{k}_{\mathrm{f}}$ increases, gas dissipation gradually dominates over accumulation caused by desorption. When $\mathrm{k}_{\mathrm{f}} / \mathrm{k}_{\mathrm{m}}$ rises up to 1000 , the pore pressure is maintained at approximately its initial value. A higher desorption rate $R_{d e}$ results in higher pore pressure along the longitudinal section of the panel due to a greater amount of gas expelled gas from the matrix.

Figure 8 presents the results for the redistribution of pore pressure induced by the different mining methods. Pore pressure is slightly decreased within the overstressed zone if its length is shorter, shown in Fig. 8a. It is worth noting that the abutment stress increases more rapidly when the length of overstressed
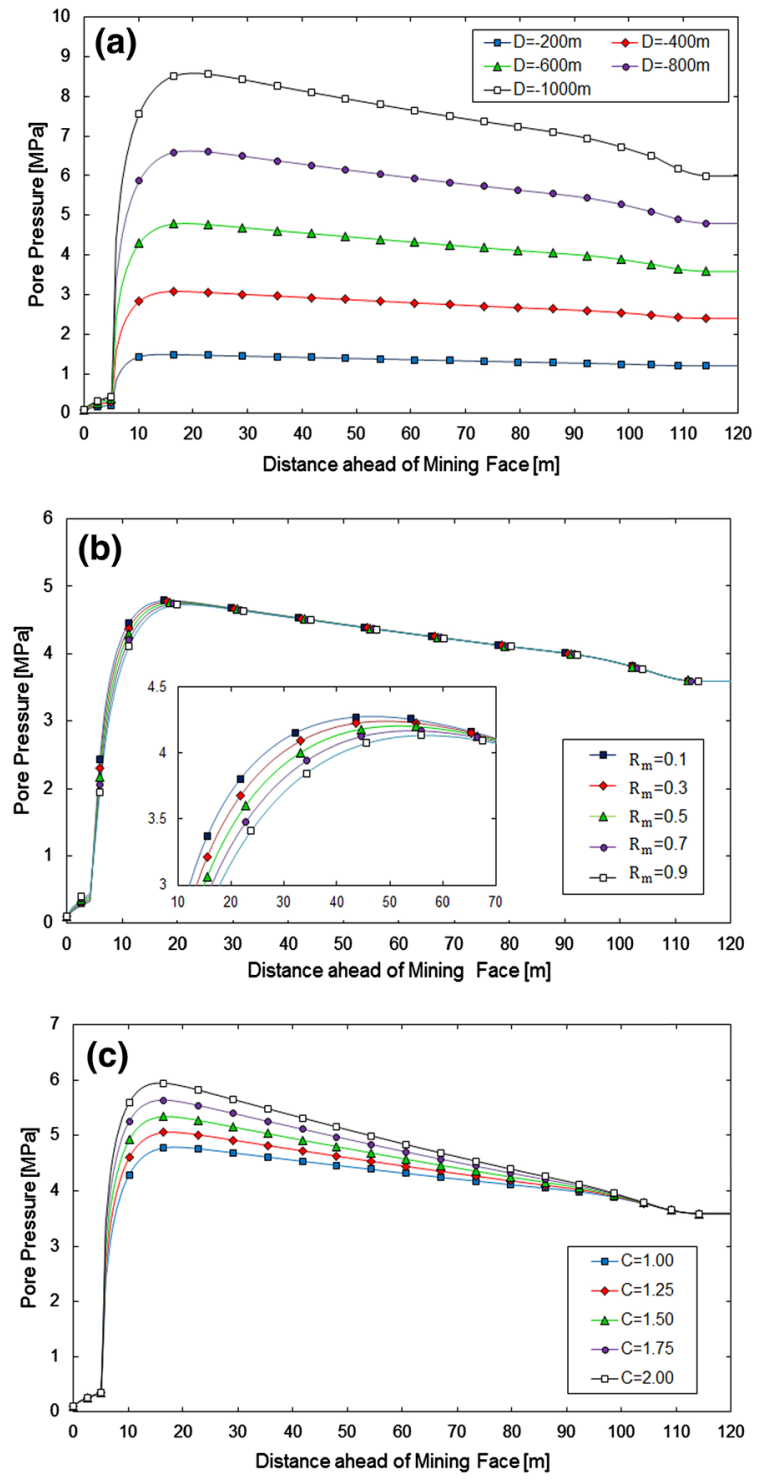

Fig. 6 Simulation results for pore pressure redistribution induced by mechanical factors: a depth $\mathrm{D}$; $\mathbf{b}$ elastic modulus reduction ratio $\mathrm{R}_{\mathrm{m}}$; and $\mathrm{c}$ stress concentration factor $\mathrm{C}$

zone is reduced. Figure $8 \mathrm{~b}$ suggests that the residual initial pressure ratio $R_{i}$ determines the magnitude of distribution of pore pressure at a specified depth. It can be inferred from Fig. $8 \mathrm{c}$ that a faster mining rate causes a greater peak pore pressure ahead of the working face, although the effect is small.

\subsection{Peak gas pressures at the face}

The peak pressure is the maximum pore pressure induced by the abutment stress in coal seam during 
Fig. 7 The simulation results for pore pressure redistribution induced by coal properties: a fracture porosity $\phi_{\mathrm{f}} ; \mathbf{b}$ permeability ratio $\mathrm{k}_{\mathrm{f}} / \mathrm{k}_{\mathrm{m}}$; and $\mathrm{c}$ desorption rate $R_{\mathrm{de}}$
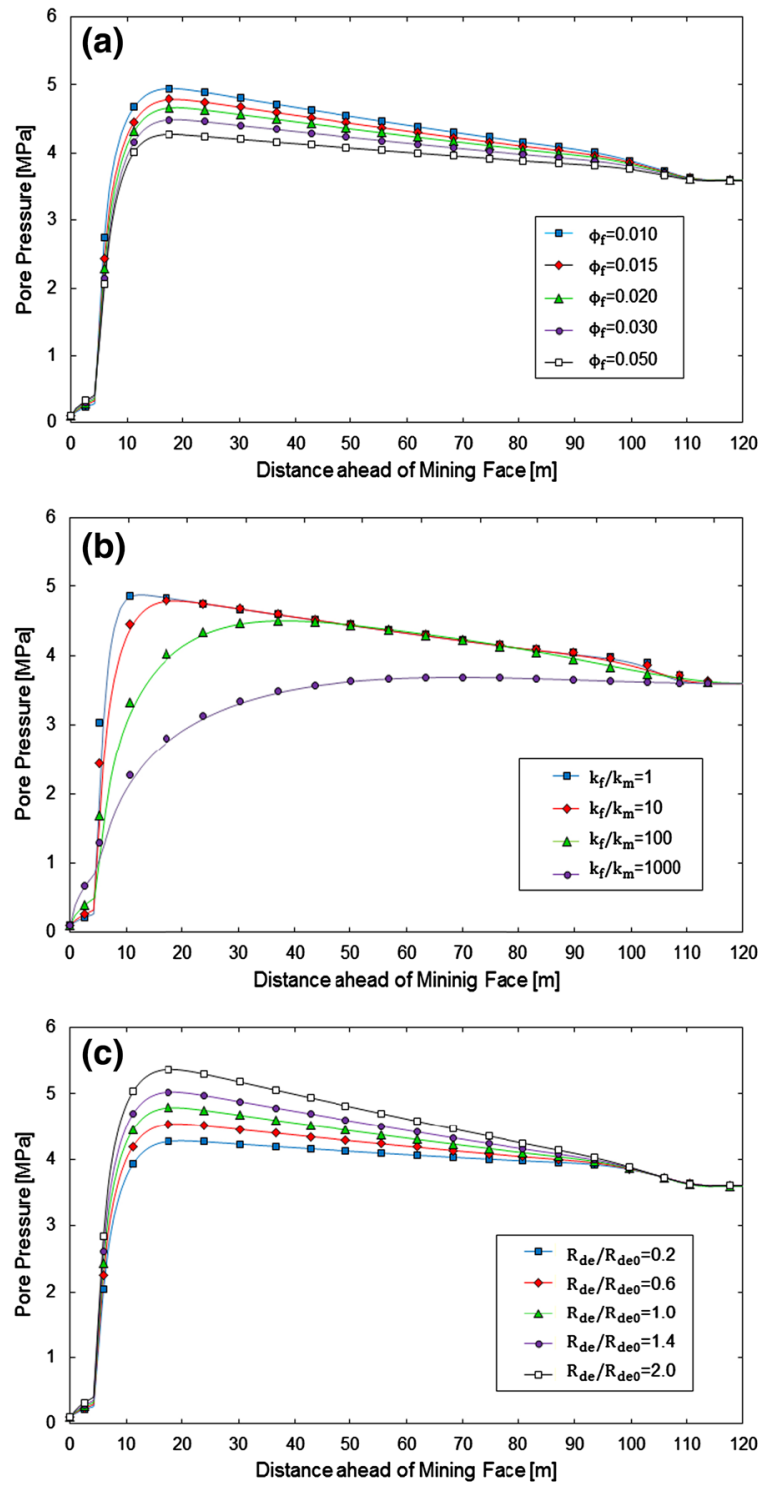

concentration $(\mathrm{C})$, desorption rate $\left(\mathrm{R}_{\mathrm{de}}\right)$ and mining rate $(\mathrm{M})$. Especially, the peak pressure occurs far from the working face in high-permeability coal seams. When $\mathrm{k}_{\mathrm{f}} / \mathrm{k}_{\mathrm{m}}=1000$, the gas dissipation dominates and no pressure increment is observed. Considered as the most influential parameter, a higher permeability significantly offsets the location of peak pressure away from the working face, significantly reducing outburst risks. Additionally, the fracture porosity $\left(\phi_{\mathrm{f}}\right)$ only has a slight impact on the position of peak pressure. Taking the length of the fractured zone into account, 

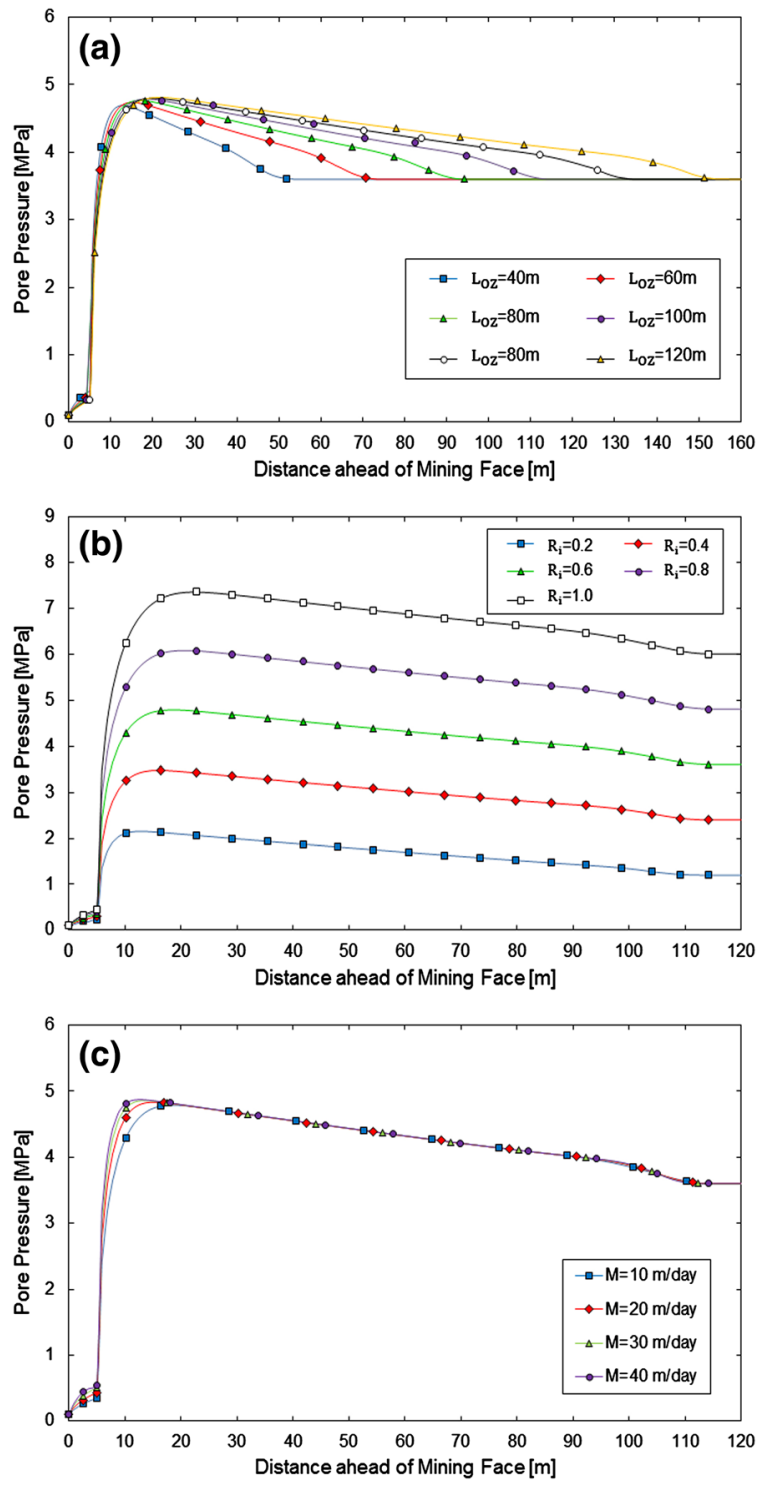

Fig. 8 Simulation results for pore pressure redistribution induced by the impacts of mining methods: a length of overstressed zone $\mathrm{L}_{\mathrm{oz}}$; b residual initial pressure ratio $\mathrm{R}_{\mathrm{i}}$; and c mining rate $M$

the locations of the occurrence of peak pressure range from $\sim 10$ to $30 \mathrm{~m}$ ahead of the working face in lowpermeability coal seams.

The increment of peak pore pressure accordingly increases with higher $\mathrm{D}, \mathrm{C}, \mathrm{R}_{\mathrm{de}}, \mathrm{L}_{\mathrm{oz}}$ and $\mathrm{M}$. Conversely, it drops with higher $\mathrm{k}_{\mathrm{f}} / \mathrm{k}_{\mathrm{m}}, \phi_{\mathrm{f}}$ and $\mathrm{R}_{\mathrm{i}}$. Moreover, the magnitude of the peak pore pressure is relatively less influenced by $\mathrm{R}_{\mathrm{m}}, \mathrm{L}_{\mathrm{oz}}$ and $\mathrm{M}$. It is worth noting that in low-permeability coal seam, $R_{m}$ has limited influence because fracture permeability would quickly decreases to the same magnitude of matrix permeability. It can be inferred that at least a $30 \%$ increment in initial pressure is induced by the abutment stress in most cases. A smaller increment in pore pressure exists only for conditions of larger fracture porosity and larger permeability.

Based on their effects, D, C, $\phi_{\mathrm{f}}, \mathrm{k}_{\mathrm{f}} / \mathrm{k}_{\mathrm{m}}, \mathrm{R}_{\mathrm{de}}$ and $\mathrm{R}_{\mathrm{i}}$ are summarized to be the first-order influential factors and $\mathrm{R}_{\mathrm{m}}, \mathrm{L}_{\mathrm{oz}}$ and $\mathrm{M}$ the second-order influential factors.

\subsection{Permeability evolution}

In this study, permeability evolution is studied in a coal seam scale. With an increasing abutment stress, the apertures of fractures gradually close and the pore space in the coal seam decreases, leading to a declines in both of fracture porosity and matrix porosity. The estimation of permeability evolution is based on the change of porosity via the cubic law. The change in porosity is mainly determined by the effective mechanical stress $\sigma_{\text {eff }}$ via the elastic modulus reduction ratio $\mathrm{R}_{\mathrm{m}}$. Figure 10 shows the change in fracture porosity changes with different $R_{m}$ values. The net strain applied to the fracture is the resultant of the mechanical strain and sorption-induced strain. Figure 11 shows how fracture porosity, matrix porosity, overall porosity and overall permeability change in the overstressed zone for $\mathrm{R}_{\mathrm{m}}=0.1$ and 0.9 . The overall permeability change is estimated by the permeability ratio $\mathrm{k} / \mathrm{k}_{0}$, where $\mathrm{k}_{0}=\mathrm{k}_{\mathrm{m} 0}+\mathrm{k}_{\mathrm{f} 0}$. The reduction in fracture porosity and matrix porosity determines the fracture and matrix permeability in a mutually independent way.

The external mechanical stress contributes the most to the compression in the coal seam, though the desorption-induced shrinkage compensates a portion of the negative strain. Figure 12 shows how the total permeability changes with the effective stress at different conditions of sorptive effects represented by different desorption rates. Higher desorption rate causes larger sorptive shrinkage in matrix, which would decrease the closure of the fracture system and result in an increment of permeability. Compared with the single-porosity linear elastic model, the reduction in permeability is 40-60\% larger in the current model. 
- Distance of Peak Pressure
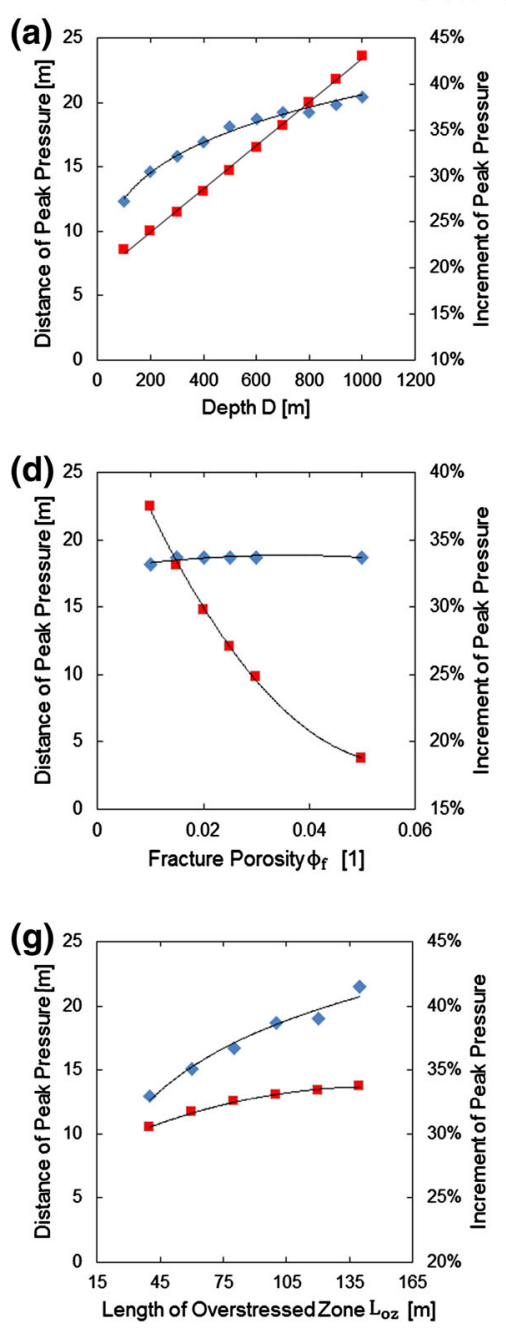

Fig. 9 The location and value of peak pressure as influenced by a depth $\mathrm{D}$, b elastic modulus reduction ratio $\mathrm{R}_{\mathrm{m}}$, c stress concentration factor $\mathrm{C}, \mathbf{d}$ fracture porosity $\phi_{\mathrm{f}}$, e permeability

\subsection{Stability analysis}

The stability of the system may be defined by considering the strength of the pillar as subjected to gas overpressures. Strength is defined in terms of effective stresses as the effective stress is depicted as (Nur 1971)

$\sigma_{\mathrm{ij}}^{\prime}=\sigma_{\mathrm{ij}}-\alpha \mathrm{p} \delta_{\mathrm{ij}}$

where $\sigma_{\mathrm{ij}}^{\prime}$ is effective stress, $\sigma_{\mathrm{ij}}$ is the abutment stress, $\mathrm{p}$ is pore pressure, $\alpha$ is the Biot coefficient, and $\delta_{\mathrm{ij}}$ is the Kronecker delta.
- Increment of Peak Pressure
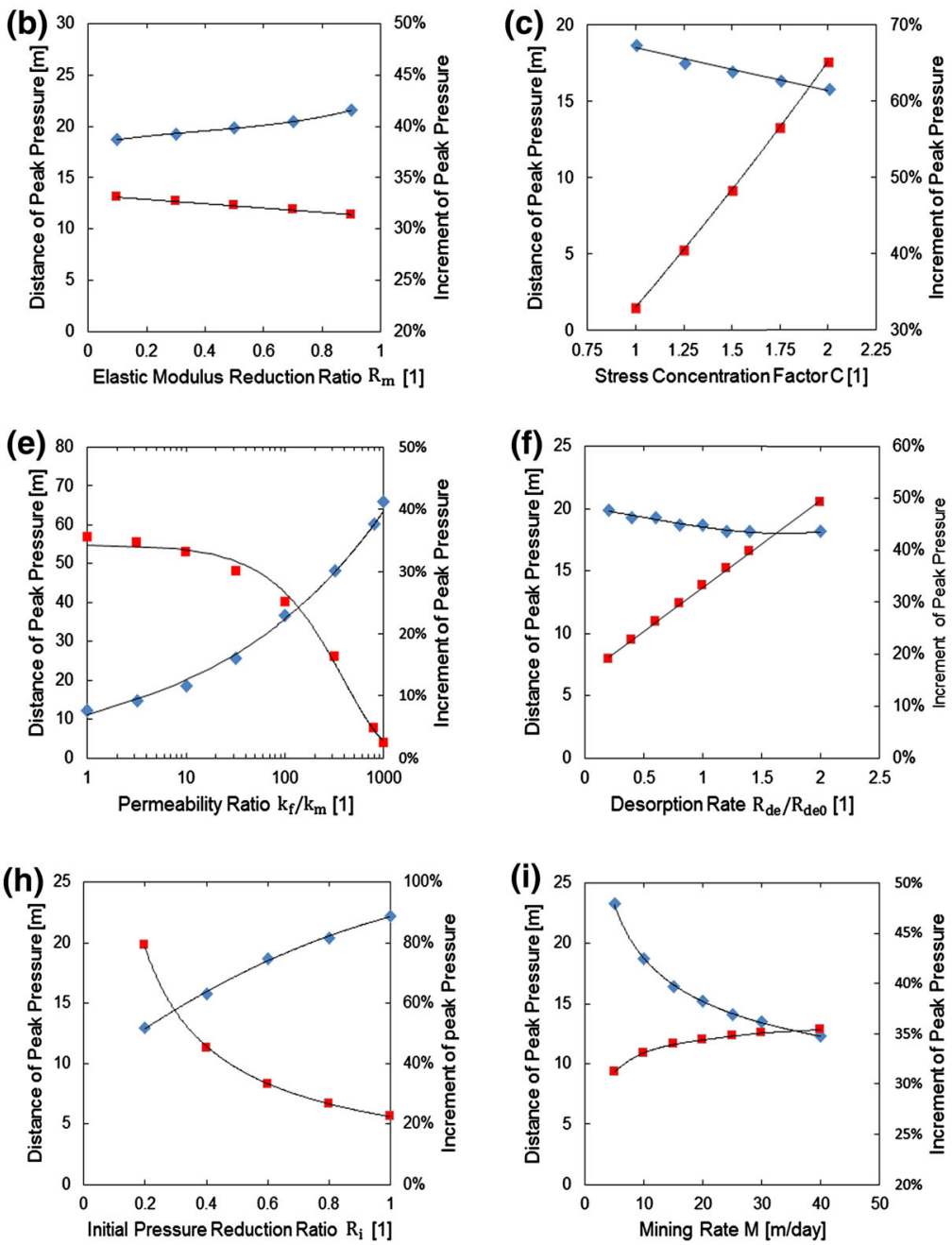

ratio $\mathrm{k}_{\mathrm{f}} / \mathrm{k}_{\mathrm{m}}, \mathbf{f}$ desorption rate $\mathrm{R}_{\mathrm{de}}, \mathbf{g}$ length of the overstressed zone $\mathrm{L}_{\mathrm{oz}}, \mathbf{h}$ residual initial pressure ratio $\mathrm{R}_{\mathrm{i}}$ and $\mathbf{i}$ mining rate $\mathrm{M}$

Assuming coal to be an elastic-plastic continuum, its failure behavior is determined by the MohrCoulomb criterion as

$\tau=\sigma \tan (\phi)+\mathrm{c}$

where $\tau$ is the shear strength of the coal, $\sigma$ is the normal stress, $\mathrm{c}$ is cohesion and $\phi$ is the angle of internal friction. In this study, $\mathrm{c}=2 \mathrm{MPa}$ and $\phi$ $=30^{\circ}$ of material is presumed unless otherwise noted. The Mohr's circle can be described by the maximum principal stress $\sigma_{1}$ and minimum principal stress $\sigma_{3}$ as $\sigma=\sigma_{\mathrm{m}}-\tau_{\mathrm{m}} \sin (\phi) ;$ 


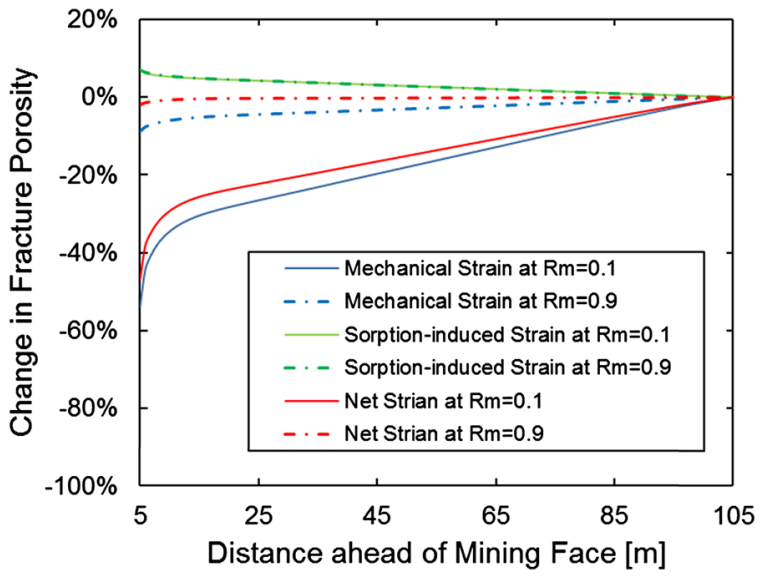

Fig. 10 Contributions to the change in fracture porosity for different values of $R_{m}$. The net strain in the fracture is the result of the combined effects of mechanical strain and sorptioninduced strain

$\tau=\tau_{\mathrm{m}} \cos (\phi)$

where $\sigma_{\mathrm{m}}=\frac{\sigma_{1}+\sigma_{3}}{2}, \tau_{\mathrm{m}}=\frac{\sigma_{1}-\sigma_{3}}{2}$, and $\phi=\left[-\frac{\pi}{2}, \frac{\pi}{2}\right]$. The factors that have impact on energetic failure include coal mechanical strength, pore pressure, permeability and loading rate. Although the residual pore pressure is lower than the initial hydrostatic pressure in the coal seam, its influence is still critical to the triggering of outbursts. The weakening effects induced by high pore pressure on the shear strength and the residual strength of coal can readily lead to the energetic breakage of coal. The condition where energetic failure occurs requires that the stored strain energy be abruptly and rapidly released. The more energy is stored, the more violent the failure is. These impacts of pore pressure are shown in Fig. 13, which has been experimentally verified (Wang et al. 2013a). Meanwhile, the negative feedback of pressure buildup can possibly trigger the occurrence of outbursts at the conditions that could previously have been safe. To determine the potential risk of outbursts, the Mohr-Coulomb criterion is utilized to calculate the shear stress along the longitudinal length of the entire overstressed zone, as shown in Fig. 14. The mechanical shear stress gradually increases from the far field to peak near the working face is- and must always be below the shear strength of coal seam. For instance, at location A, $39.4 \mathrm{~m}$ ahead of the working face, the pore pressure of $5.6 \mathrm{MPa}$ is not sufficient to trigger an outburst. However, as the abutment stress and pore pressure continue to increase, the effective shear stress rises up to a peak shear strength and results in an unstable failure at location $\mathrm{B}, 25.8 \mathrm{~m}$ ahead of the working face (very close to the position of peak pressure), with a pore pressure of 5.8 MPa. This mechanism in particular is illustrated in Fig. 15.

Other factors can influence the failure criteria as well. Loading rate, for instance, has a positive correlation with strain hardening (Hashiba et al. 2006; Okubo et al. 2006; Wang et al. 2013a). Higher loading rates increase the peak strength of coal, presumably because there is less time available for new fractures to develop. Recent studies imply that coal with lower permeability is subjected to higher degree of fragmentation when fails (Wang et al. 2015). The gas dissipation is hindered by an impermeable fracture network when gas desorption behavior occurs. Thus, low-permeability coal is prone to severely energetic rupture.
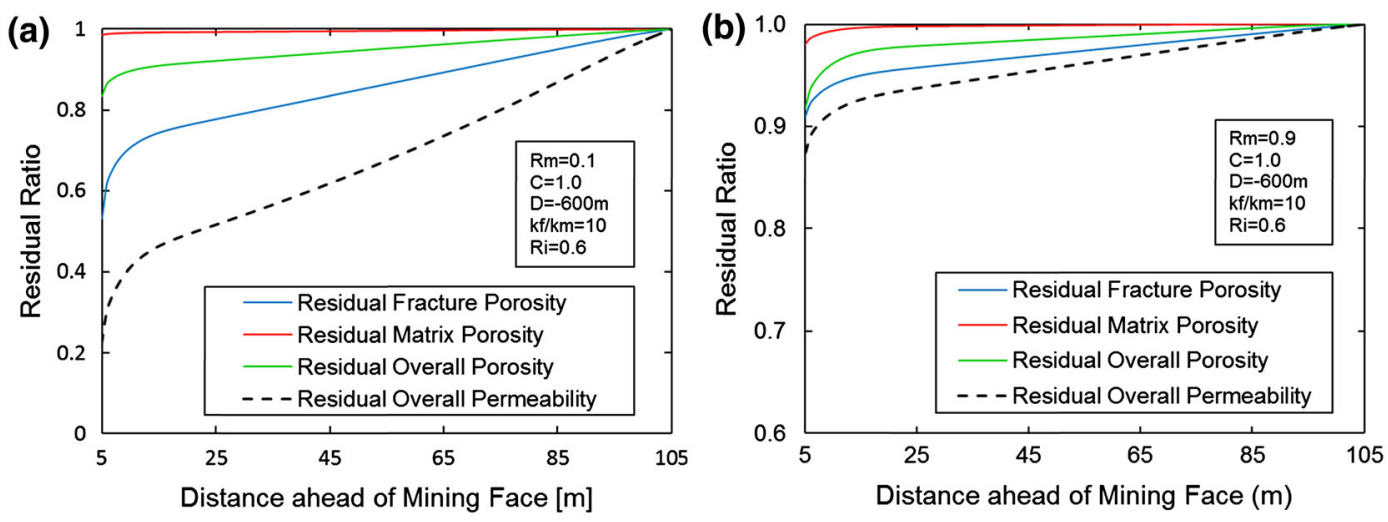

Fig. 11 Changes in fracture porosity, matrix porosity and permeability in the overstressed zone at $R_{m}=0.1$ and 0.9 


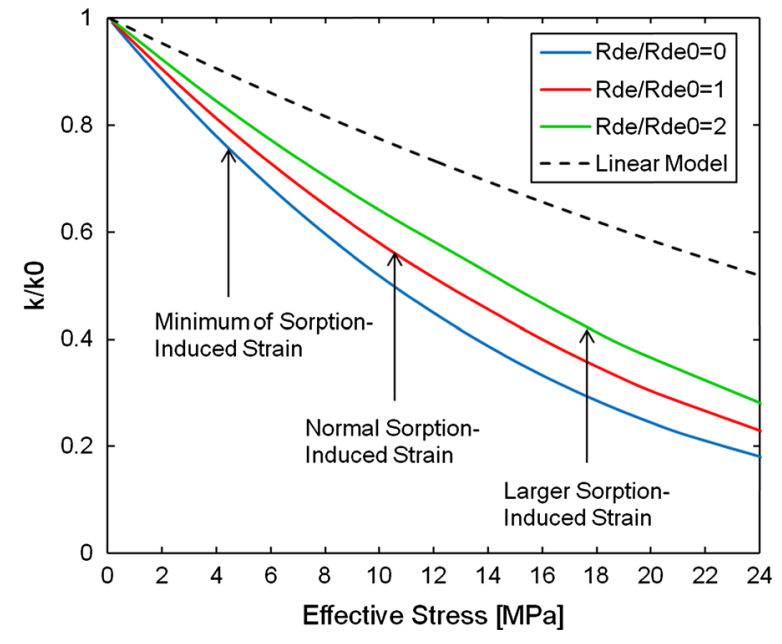

Fig. 12 The permeability ratio $\mathrm{k} / \mathrm{k}_{0}$ versus the effective stress at different desorption rates. Compared with the simple linear elastic model, the dual-porosity dual-permeability dual stiffness model yields a 40-60\% larger estimation of the reduction in permeability

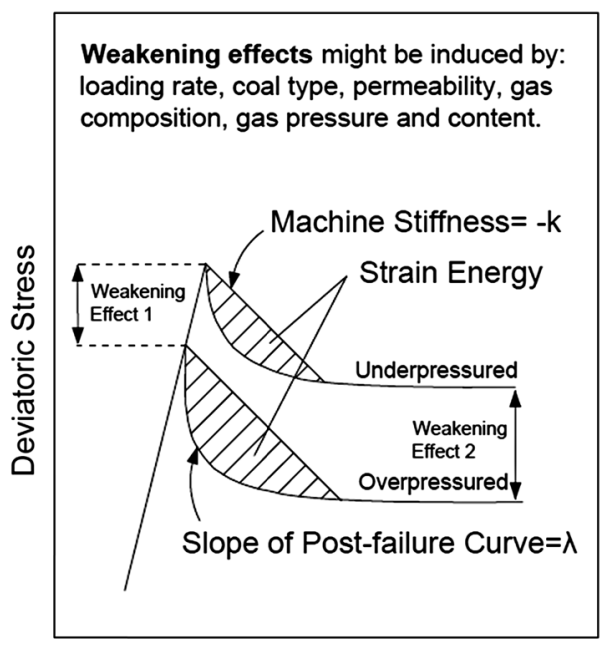

Axial Strain

Fig. 13 A conceptual model illustrating the role of pore pressure in initiating an energetic failure. Energetic failure occurs when the stored strain energy is abruptly released. The strain energy is stored on the condition that $\lambda+\mathrm{k}<0$. The more energy that is stored, the more violent the failure. The high pore pressure also engenders weakening effects at the maximum of shear strength (WE1) and the residual shear strength of coal (WE2). These weakening effects make coal more vulnerable, being more easily broken at a lower stress state

\subsection{Dimensionless analysis}

To investigate the tendency of pressure changing in an unsealed condition with mass flux, three dimensionless terms are defined in Eq. (29) as

$$
\left\{\begin{array}{l}
\mathrm{P}_{\mathrm{D}}=\frac{\rho \mathrm{P}}{\mu \mathrm{Q}} \\
\mathrm{t}_{\mathrm{D}}=\frac{\mathrm{t}}{\mu \mathrm{S}} \\
\mathrm{x}_{\mathrm{D}}=\frac{\mathrm{x}}{\sqrt{\mathrm{k}}}
\end{array}\right.
$$

where $\rho$ is the density of the fluid, $P$ is pore pressure, $\mu$ is the dynamic viscosity of the fluid, $Q$ is the mass source, $\mathrm{t}$ is time, $\mathrm{S}$ is the storage coefficient defined by $\phi \cdot \chi_{f}, \chi_{f}$ is the compressibility of the fluid, $\mathrm{x}$ is the longitudinal distance from the working face and $\mathrm{k}$ is the permeability of coal.

Thus, Eq. (4), the time-dependent mass balance governing equation, is transformed into

$$
\frac{\partial \mathrm{P}_{\mathrm{D}}}{\partial \mathrm{t}_{\mathrm{D}}}-\frac{\partial^{2} \mathrm{P}_{\mathrm{D}}}{\partial \mathrm{x}_{\mathrm{D}}^{2}}=1
$$

The analytical solution of Eq. (30) is given as (Carlslaw and Jaeger 1959)

$$
\begin{aligned}
P_{D}= & \left(0+t_{D}+\frac{1}{2} x_{D}^{2}\right) \operatorname{erf}\left(\frac{x_{D}}{2 \sqrt{t}}\right)+x_{D}\left(\frac{t_{D}}{\pi}\right)^{\frac{1}{2}} e^{-\frac{x_{D}^{2}}{4 t_{D}}} \\
& -\frac{x_{D}^{2}}{2}
\end{aligned}
$$

with $\mathrm{P}_{\mathrm{D}}=0$, when $\mathrm{t}_{\mathrm{D}}=0$

$\mathrm{P}_{\mathrm{D}}=0$, when $\mathrm{x}_{\mathrm{D}}=0, \mathrm{t}_{\mathrm{D}}>0$

Divided by $t_{D}$, a function $P_{D} / t_{D}=f\left(x_{D}^{2} / t_{D}\right)$ can be derived from Eq. (31) as

$$
\begin{aligned}
\frac{\mathrm{P}_{\mathrm{D}}}{\mathrm{t}_{\mathrm{D}}}= & \left(0+1+\frac{1}{2} \frac{\mathrm{x}_{\mathrm{D}}^{2}}{\mathrm{t}_{\mathrm{D}}}\right) \operatorname{erf}\left(\frac{1}{2} \sqrt{\frac{\mathrm{x}_{\mathrm{D}}^{2}}{\mathrm{t}_{\mathrm{D}}}}\right)+\left(\frac{\mathrm{x}_{\mathrm{D}}^{2}}{\mathrm{t}_{\mathrm{D}} \pi}\right)^{\frac{1}{2}} \mathrm{e}^{-\frac{1 \mathrm{x}_{\mathrm{D}}^{2}}{4 \mathrm{t}_{\mathrm{D}}}} \\
& -\frac{1}{2} \frac{\mathrm{x}_{\mathrm{D}}^{2}}{\mathrm{t}_{\mathrm{D}}}
\end{aligned}
$$

The dimensionless parameter $\mathrm{P}_{\mathrm{D}} / \mathrm{t}_{\mathrm{D}}$ changes from 0 to 1 with $\mathrm{x}_{\mathrm{D}}^{2} / \mathrm{t}_{\mathrm{D}}$ increasing as shown in Fig. $16 \mathrm{a}$. $\mathrm{P}_{\mathrm{D}} / \mathrm{t}_{\mathrm{D}}$ reaches 72 and $99 \%$ of the steady magnitude of $\mathrm{P}_{\mathrm{D}} /$ 


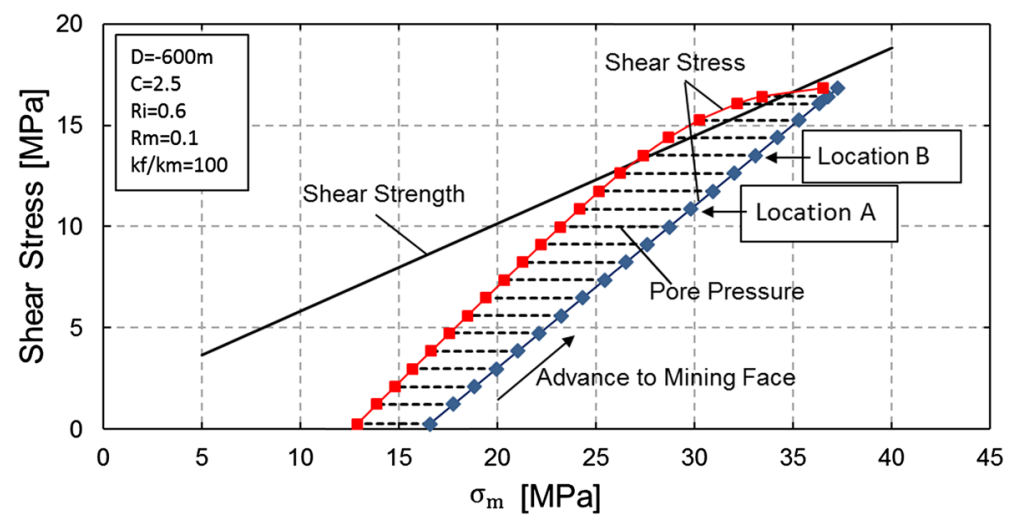

Fig. 14 Schematic of the feedback of pore pressure on the occurrence of failure. The blue line shows the distribution of shear stress applied to the drained coal seam. When pore pressure is applied (black dash line), the shear stresses are
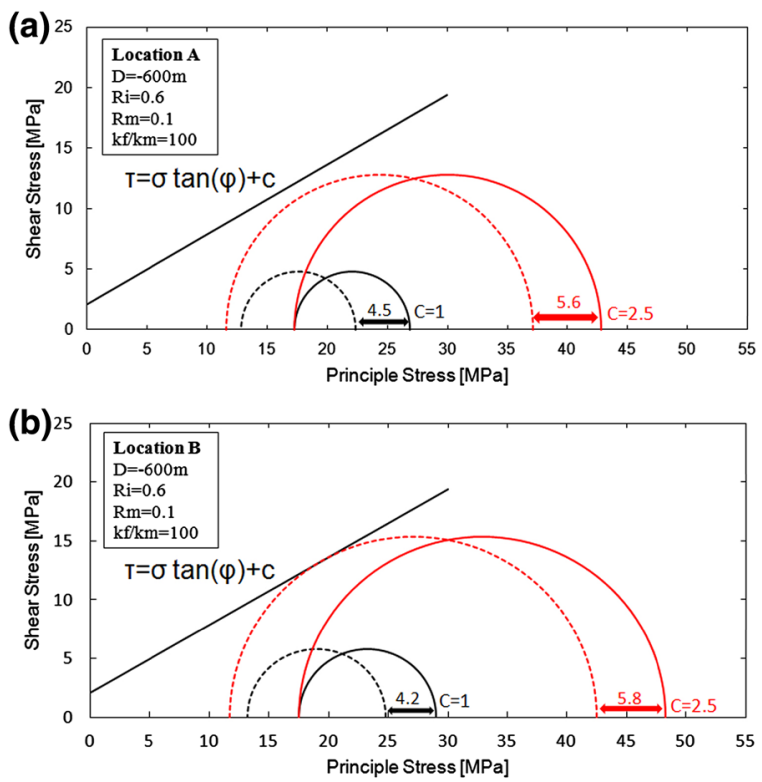

Fig. 15 Mohr's circles representing locations A $(x=39.4 \mathrm{~m})$ and $\mathrm{B}(\mathrm{x}=25.8 \mathrm{~m})$. The value of mining-induced stress is determined by $\mathrm{C}$. When $\mathrm{C}=1$, the stress at either location $\mathrm{A}$ or $\mathrm{B}$ is less than the strength of the coal. But as $\mathrm{C}$ increasing, the Mohr's circle gradually approaches the strength envelope. When $\mathrm{C}$ rises to 2.5, the shear stress at location $\mathrm{A}$ is still lower than its shear strength. Nevertheless, failure occurs at location B as a result of the effective shear strength being exceeded

$t_{D}=1$ with $x-{ }_{D}^{2} / t_{D}=1$ and 10 of the face, respectively. Figure $16 \mathrm{~b}$ shows the relationship between the dimensionless distance and the distance in the numerical solution under different conditions of $\mathrm{k}_{\mathrm{f}} / \mathrm{k}_{\mathrm{m}}$. It is inferred that $\mathrm{x}_{\mathrm{D}}^{2} / \mathrm{t}_{\mathrm{D}}=[1,10]$ represents the range of a modified as shown (red curve). The overlap between the red curve of shear stress and the black solid line of shear strength shows that the shear stress exceeds the shear strength of coal seam

high level of pressure existing ahead of the working face. Therefore, The range of the critical distance for high pore pressure is estimated as $\left[\sqrt{\frac{\mathrm{kt}}{\mu \mathrm{S}}}, 3.16 \sqrt{\frac{\mathrm{kt}}{\mu \mathrm{S}}}\right]$.

\subsection{Drainage analysis}

Pre-drainage is considered to be the most effective measure against outburst proneness. The in-seam drainage before mining advance can efficiently reduce the increment of pore pressure induced by abutment stress and gas desorption. The most commonly used drainage methods include natural dissipation, directional borehole drilling, water infusion and surface well drainage (Lama and Bodziony 1998). Coalbed methane naturally dissipates through coal walls due to the pressure gradient. The dissipated methane is diluted and carried out by ventilation equipment. Generally, mining will not be proceeded until the residual pressure within the coal seam is naturally lowered to a safe level. Directional borehole drilling is a method that is used to create and extend an artificial fracture network in order to obtain pressure relief. It includes the drilling of horizontal boreholes from working face and sides of the panel, and the drilling of boreholes connected to the vertical shaft with various angels (Wang et al. 2013a, b, c). Water infusion is a subsequent method to increase the moisture content in coal seams after borehole drilling but only for a limited distance. High-pressure water up to $25 \mathrm{MPa}$ can be injected into the boreholes to saturate the coal 

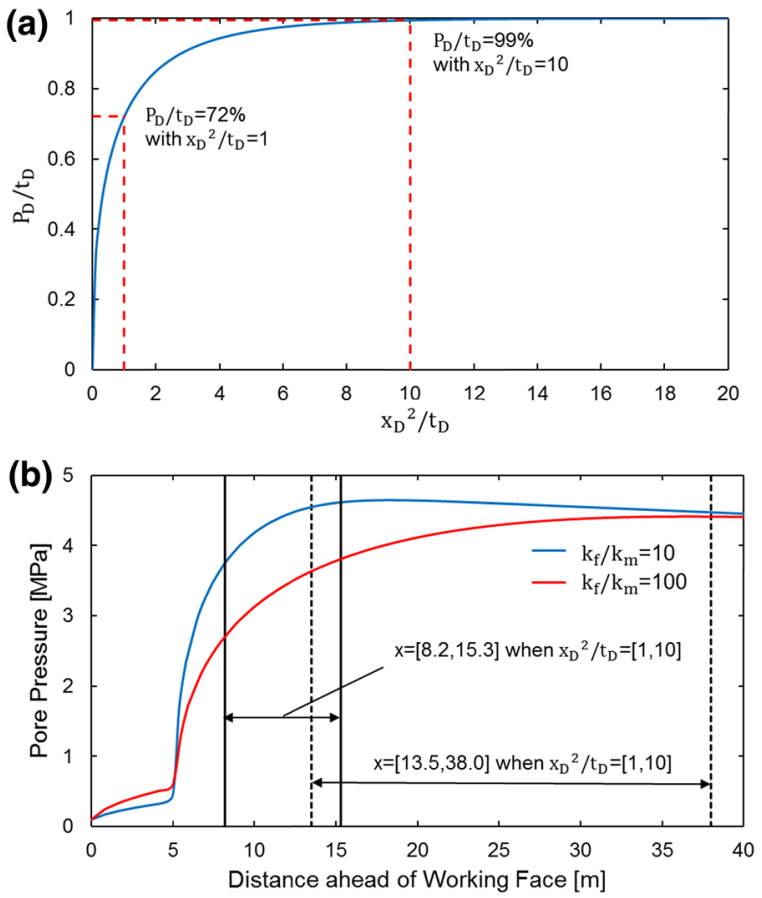

Fig. 16 a The analytical solution of the time-dependent mass balance governing equation. The dimensionless pressures reach 72 and $99 \%$ of the steady magnitude of $\mathrm{P}_{\mathrm{D}} / \mathrm{t}_{\mathrm{D}}=1$ with the dimensionless distance $x_{D}^{2} / t_{D}=1$ and 10 of the face, respectively. $\mathbf{b}$ The distance ahead of the working face in the numerical solution compares with the range of the critical distance $\left[\sqrt{\frac{\mathrm{kt}}{\mu \mathrm{S}}}, 3.16 \sqrt{\frac{\mathrm{kt}}{\mu \mathrm{S}}}\right]$

seam (Díaz Aguado and González Nicieza 2007). It is believed that the competitive sorption of water to the coal will deactivate the gas desorption behavior in coal seams. Meanwhile, more permanent non-recoverable strain energy is accumulated instead of elastic strain energy in the saturated area (Beamish and Crosdale 1998; Díaz Aguado and González Nicieza 2007). In addition, methane drainage via surface wells is a method used for the long-period (E)CBM production (Sang et al. 2010). For coal seams with abundant methane, surface well drainage can not only lower the outburst risk by reducing pore pressure, but can also exploit methane as an energy resource.

In this study, the effect of drainage measures is represented by the length of the drainage zone. In the drained zone, a larger permeability ratio and lower initial pore pressure are presumed $\left(\mathrm{k}_{\mathrm{f}} / \mathrm{k}_{\mathrm{m}}=1000\right.$ and $\left.R_{i}=0.1\right)$. The length of the drainage zone represents the effective range of boreholes. The pore pressure distributions in three cases with different lengths of the

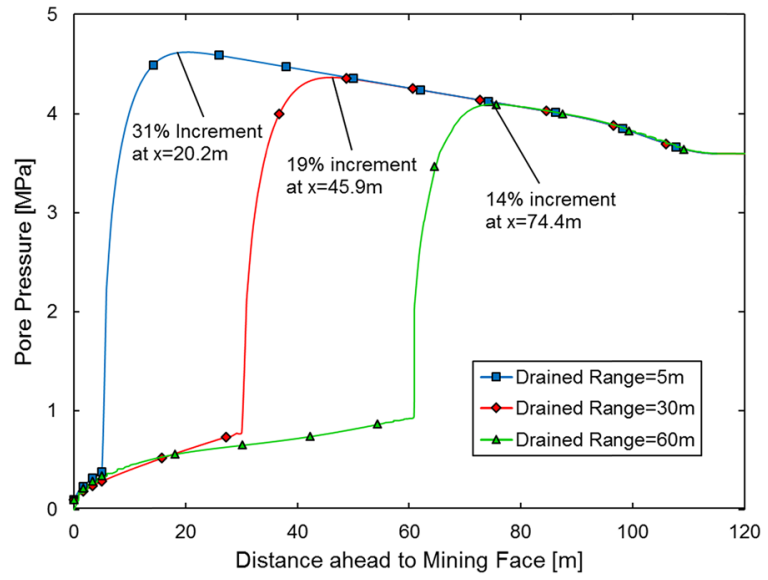

Fig. 17 The pore pressure distribution for different drainage conditions. With an increase in the depth of drainage, the location of the peak pressure is shifted further from the working face. The maximum peak pressure magnitude also decreases for a longer drainage zone

drainage zone are shown in Fig. 17. The peak pressure is shifted further from the working face with a larger drained range. The peak pressure is also reduced by increasing the length of the drainage zone. In these examples, the residual pore pressure in the drained zone remains under $1 \mathrm{MPa}$, which is consistent with the field data for coal mine safety.

Except the natural properties of coal, there are five controllable parameters including $\mathrm{C}, \phi_{\mathrm{f}}, \mathrm{k}_{\mathrm{f}} / \mathrm{k}_{\mathrm{m}}, \mathrm{R}_{\mathrm{i}}$ and $\mathrm{M}$ in the parametric study. Drainage methods discussed above positively influence $\phi_{\mathrm{f}}, \mathrm{k}_{\mathrm{f}} / \mathrm{k}_{\mathrm{m}}$ and $\mathrm{R}_{\mathrm{i}}$ to reduce the potential accumulation of coalbed methane. Because of the negative impacts of fast mining rate, mining activities should slow down or completely stop once an unusually high gas pressure is observed within the coal seam ahead of the working face. To reduce the outburst risk from stress concentration, specified technologies and mining methods need to be utilized, especially when encountering geological anomalies, stress overlap and periodical weighting (Lama and Bodziony 1998).

\section{Conclusions}

Gas desorption induced by elevated abutment stress is highlighted in this study as the main reason for the generation of high excess gas pressures ahead of the face that triggers the occurrence of outbursts during underground coal mining. The redistribution of pore 
pressure is determined by the complex competition between the gas accumulation and dissipation. In this study, a numerical model is developed to investigate the pore pressure distribution ahead of the working face, where coal is considered as a dual porosity-dual permeability-dual stiffness continuum. The results derived from 49 contrasting parametric studies with nine different influential variables show that:

1. Pore pressure firstly increases from its initial value to a peak and then decreases to atmospheric pressure at the working face. This pattern of pressure redistribution ahead of the working face is widely observed except in the high-permeability case $\left(\mathrm{k}_{\mathrm{f}} / \mathrm{k}_{\mathrm{m}}=1000\right)$. Based on the study of peak pressure, high pore pressure possibly exists very close to the working face when one or several extreme conditions are aligned in the coal seam. In the most cases, a $\sim 20$ to $\sim 80 \%$ increase of pore pressure is observed in the zone from 10 to $30 \mathrm{~m}$ ahead of the working face.

2. The most influential factors in this model are summarized into two categories. The first-order influential factors are $\mathrm{D}, \mathrm{C}, \phi_{\mathrm{f}}, \mathrm{k}_{\mathrm{f}} / \mathrm{k}_{\mathrm{m}}, \mathrm{R}_{\mathrm{de}}, \mathrm{R}_{\mathrm{i}}$ and the second-order influential factors are $\mathrm{R}_{\mathrm{m}}, \mathrm{L}_{\mathrm{oz}}$ and $\mathrm{M}$. Besides the natural properties of coal seam, the controllable factors contain $\mathrm{C}, \phi_{\mathrm{f}}, \mathrm{k}_{\mathrm{f}} / \mathrm{k}_{\mathrm{m}}$, $\mathrm{R}_{\mathrm{i}}$ and $\mathrm{M}$ that may be taken into consideration in outburst management.

3. Permeability evolution is studied at the coal seam scale. The change in fracture porosity is the resultant of both desorption-induced shrinkage and mechanical compression. In a dual-porosity medium, the total reduction in porosity is the cumulative result of the reduction in both the fracture and matrix porosity. The alteration in permeability is correlated to the change in porosity following the cubic law. In the default case, a $17 \%$ reduction in porosity results in an $88 \%$ reduction in permeability. Compared with the single-porosity linear elastic model, the current model results in a larger decrease in permeability as the effective stress increases.

4. High pore pressure may trigger the occurrence of energetic outbursts in the two ways: (a) by unstable failure due to the feedback of pore pressure where the drained coal seam could previously have been safe; (b) by the weakening effects on the peak shear strength and the residual shear strength, accumulating a larger strain energy. Using the Mohr-Coulomb criterion, the location of a potential violent outburst can be predicted during mining advance. Pre-drainage is considered to be the most effective way to diminish the outburst risk. The results of drainage cases suggest that increasing the size of the drained zone reduces outburst proneness.

5. In scaling analysis, the dimensionless pressure $\mathrm{P}_{\mathrm{D}}$, dimensionless distance $\mathrm{x}_{\mathrm{D}}$ and dimensionless time $t_{D}$ are defined to investigate the tendency of pressure change in an unsealed condition with uniform applied mass flux. The analytical solution of $\mathrm{P}_{\mathrm{D}} / \mathrm{t}_{\mathrm{D}}$ as a function of $\mathrm{x}_{\mathrm{D}}^{2} / \mathrm{t}_{\mathrm{D}}$ depicts the feature of pressure distribution. A critical range of distances ahead of the mining face is suggested to be $\left[\sqrt{\frac{\mathrm{kt}}{\mu \mathrm{S}}}, 3.16 \sqrt{\frac{\mathrm{kt}}{\mu \mathrm{S}}}\right]$ where the high pore pressure prevails.

Acknowledgment This work is a partial result of funding by NIOSH under contract 200-2008-25702, and the National Science Foundation under grant EAR-0842134. This support is gratefully acknowledged. The authors also thank anonymous reviewers for their constructive comments which have helped to improve the manuscript.

\section{References}

An FH, Cheng YP (2014) An explanation of large-scale coal and gas outbursts in underground coal mines: the effect of lowpermeability zones on abnormally abundant gas. Nat Hazards Earth Syst Sci 14:2125-2132. doi:10.5194/nhess14-2125-2014

Bai M, Meng F, Elsworth D, Abousleiman Y, Roegiers JC (1999) Numerical modelling of coupled flow and deformation in fractured rock specimens. Int J Numer Anal Methods Geomech 23(2):141-160

Beamish BB, Crosdale PJ (1998) Instantaneous outbursts in underground coal mines: an overview and association with coal type. Int J Coal Geol 35(1-4):27-55. doi:10.1016/ S0166-5162(97)00036-0

Biot MA (1941) General theory of three-dimensional consolidation. J Appl Phys 12(2):155-164. doi:10.1063/1. 1712886

Cao Y, He D, Glick DC (2001) Coal and gas outbursts in footwalls of reverse faults. Int J Coal Geol 48(1-2):47-63. doi:10.1016/S0166-5162(01)00037-4

Carlslaw HS, Jaeger JC (1959) Conduction of heat in solids, 2nd edn. Clarendon Press, Oxford

Chen Z, Liu J, Pan Z, Connell LD, Elsworth D (2012) Influence of the effective stress coefficient and sorption-induced strain on the evolution of coal permeability: model 
development and analysis. Int $\mathrm{J}$ Greenh Gas Control 8(5):101-110. doi:10.1016/j.ijggc.2012.01.015

Cui X, Bustin RM (2005) Volumetric strain associated with methane desorption and its impact on coalbed gas production from deep coal seams. AAPG Bull 89(9):11811202. doi:10.1306/05110504114

Díaz Aguado MB, González Nicieza C (2007) Control and prevention of gas outbursts in coal mines, Riosa-Olloniego coalfield, Spain. Int J Coal Geol 69(4):253-266. doi:10. 1016/j.coal.2006.05.004

Durucan S, Edwards JS (1986) The effects of stress and fracturing on permeability of coal. Min Sci Technol 3(3):205216. doi:10.1016/S0167-9031(86)90357-9

Elsworth D, Bai M (1992) Flow-deformation response of dualpo-rosity media. J Geotech Eng. doi:10.1061/(ASCE) 0733-9410(1992)118:1(107),107-124

Harpalani S, Mitra A (2010) Impact of $\mathrm{CO}_{2}$ injection on flow behavior of coalbed methane reservoirs. Transp Porous Media 82(1):141-156. doi:10.1007/s11242-009-9475-1

Harpalani S, Schraufnagel R (1990) Shrinkage of coal matrix with release of gas and its impact on permeability of coal. Fuel 69(5):551-556. doi:10.1016/0016-2361(90)90137-F

Harvey C (2002) History of outbursts in Australia and current management controls. In: Aziz N (ed) Coal operators' conference, University of Wollongong \& the Australasian, Institute of Mining and Metallurgy, pp 36-46

Hashiba K, Okubo S, Fukui K (2006) A new testing method for investigating the loading rate dependency of peak and residual rock strength. Int $J$ Rock Mech Min Sci 43(6):894-904. doi:10.1016/j.ijrmms.2005.12.005

Hol S, Peach CJ, Spiers CJ (2011) A new experimental method to determine the $\mathrm{CO}_{2}$ sorption capacity of coal. Energy Procedia 4(1):3125-3130. doi:10.1016/j.egypro.2011.02.226

Hol S, Peach CJ, Spiers CJ (2012) Effect of 3-D stress state on adsorption of $\mathrm{CO}_{2}$ by coal. Int J Coal Geol 93:1-15. doi:10. 1016/j.coal.2012.01.001

Jasinge D, Ranjith PG, Choi SK (2011) Effects of effective stress changes on permeability of latrobe valley brown coal. Fuel 90(3):1292-1300. doi:10.1016/j.fuel.2010.10. 053

Jasinge D, Ranjith PG, Choi X, Fernando J (2012) Investigation of the influence of coal swelling on permeability characteristics using natural brown coal and reconstituted brown coal specimens. Energy 39(2012):303-309

Khristianovich SA (1953) Distribution of gas pressure close to an advancing coal face. Irv ANUSSR Otd Tekhn Nauk (12):1673-1678 (in Russian)

Krooss BM, Van Bergen F, Gensterblum Y, Siemons N, Pagnier HJM, David P (2002) High-pressure methane and carbon dioxide adsorption on dry and moisture-equilibrated Pennsylvanian coals. Int J Coal Geol 51:69-92. doi:10. 1016/S0166-5162(02)00078-2

Lama RD, Bodziony J (1998) Management of outburst in underground coal mines. Int J Coal Geol 35(1-4):83-115. doi:10.1016/S0166-5162(97)00037-2

Lama R, Saghafi A (2002) Overview of gas outbursts and unusual emissions. In: Third Australasian coal operators conference, Wollongong, Australia

Liu S, Harpalani S (2013) A new theoretical approach to model sorption induced coal shrinkage or swelling. AAPG Bull 7(7):1033-1049. doi:10.1306/12181212061
Liu J, Chen Z, Elsworth D, Miao X, Mao X (2011) Evolution of coal permeability from stress-controlled to displacementcontrolled swelling conditions. Fuel 90(10):2987-2997. doi:10.1016/j.fuel.2011.04.032

Mukherjee C, Sheorey PR, Sharma KG (1994) Numerical simulation of caved goaf behaviour in longwall workings. Int J Rock 31(I):35-45. http://www.sciencedirect.com/ science/article/pii/0148906294923132

Nur A (1971) An exact effective stress law for elastic deformation of rock with fluids. J Geophys Res: Solid Earth 76(26):6414-6419

Okubo S, Fukui K, Qingxin Q (2006) Uniaxial compression and tension tests of anthracite and loading rate dependence of peak strength. Int J Coal Geol 68(3-4):196-204. doi:10. 1016/j.coal.2006.02.004

Palmer I, Mansoori J (1996) How permeability depends on stress and pore pressure in coalbeds: a new model. SPE Reserv Eval Eng 1(1998):539-544

Pan Z, Connell LD (2007) A theoretical model for gas adsorption-induced coal swelling. Int J Coal Geol 69(4):243-252. doi:10.1016/j.coal.2006.04.006

Paterson L (1986) A model for outbursts in coal. Int J Rock Mech Min Sci Geomech Abstr 23(4):327-332. doi:10. 1016/0148-9062(86)90644-3

Perera M, Ranjith PG, Choi SK (2013) Coal cleat permeability for gas movement under triaxial, non-zero lateral strain condition: atheoretical and experimental study. Fuel 109(2013):389-399

Pone JDN, Halleck PM, Mathews JP (2009) Sorption capacity and sorption kinetic measurements of $\mathrm{CO}_{2}$ and $\mathrm{CH}_{4}$ in confined and unconfined bituminous coal. Energy Fuels 23(9):4688-4695. doi:10.1021/ef9003158

Richards MJ (1984) Longwall front abutment stress effects firedamp release. Min Sci Technol 1:215-229. doi:10. 1016/S0167-9031(84)90425-0

Robertson E, Christiansen R (2007) Modeling laboratory permeability in coal using sorption-induced-strain data. SPE Reserv Eval Eng 10(3):9-12. doi:10.2118/97068-PA

Sang S, Xu H, Fang L, Li G, Huang H (2010) Stress relief coalbed methane drainage by surface vertical wells in China. Int J Coal Geol 82(3-4):196-203. doi:10.1016/j. coal.2009.10.016

Seidle JP, Huitt LG (1995) Experimental measurement of coal matrix shrinkage due to gas desorption and implications for cleat permeability increases. Paper SPE 30010. In: Proceedings of SPE international meeting on petroleum engineering, Beijing, China

Sheorey PR (1994) A theory for in situ stresses in isotropic and transversely isotropic rock. Int J Rock Mech Min Sci Geomech Abstr 31(1):23-34. doi:10.1016/0148-9062 (94)91070-7

Shepherd J, Rixon LK, Griffiths L (1981) Outbursts and geological structures in coal mines: a review. Int J Rock Mech Min Sci Geomech Abstr 18(4):267-283. doi:10.1016/ 0148-9062(81)91192-X

Shi J-Q, Durucan S (2005) A model for changes in coalbed permeability during primary and enhanced methane recovery. SPE Reserv Eval Eng. doi:10.2118/87230-PA

Somerton WH, Soylemezolu IM, Dudley RC (1975) Effect of stress on permeability of coal. International Journal of Rock Mechanics and Mining Science \& Geomechanics Abstracts 12(cm):129-145 
Thin IGT, Pine RJ, Trueman R (1993) Numerical modelling as an aid to the determination of the stress distribution in the goaf due to longwall coal mining. Int J Rock Mech Min Sci Geomech Abstr 30(7):1403-1409. doi:10.1016/0148-9062(93)90128-Z

Van Golf-Racht TD (1982) Fundamentals of fractured reservoir engineering. Elsevier, Amsterdam

Wang S, Elsworth D, Liu J (2012) A mechanistic model for permeability evolution in dual permeability dual stiffness sorbing media. J Geophys Res 117:B06205. doi:10.1029/ 2011JB008855

Wang L, Cheng YP, Ge CG, Chen JX, Li W, Zhou HX, Hai-feng W (2013a) Safety technologies for the excavation of coal and gas outburst-prone coal seams in deep shafts. Int $\mathbf{J}$ Rock Mech Min Sci 57:24-33. doi:10.1016/j.ijrmms.2012. 08.006

Wang S, Elsworth D, Liu J (2013b) Mechanical behavior of methane infiltrated coal: the roles of gas desorption, stress level and loading rate. Rock Mech Rock Eng 46(5):945958. doi:10.1007/s00603-012-0324-0

Wang S, Elsworth D, Liu J (2013c) Permeability evolution during progressive deformation of intact coal and implications for instability in underground coal seams. Int $\mathrm{J}$ Rock Mech Min Sci 58:34-45. doi:10.1016/j.ijrmms.2012. 09.005
Wang S, Elsworth D, Liu J (2015) Rapid decompression and desorption induced energetic failure in coal. J Rock Mech Geotech Eng 7(3):345-350

Warren JE, Root PJ (1963) The behavior of naturally fractured reservoirs. Soc Petrol Eng J 3(3):245-255. doi:10.2118/ 426-PA

Williams R, Weissman J (1995) Gas emission and outburst assessment in mixed $\mathrm{CO}_{2}$ and $\mathrm{CH}_{4}$ environments. In: ACIRL seminar-prosperity with safety in a hostile environment, Brisbane, University of New South Wales, pp 1-13

Wu Y, Liu J, Chen Z, Elsworth D, Pone D (2011) A dual poroelastic model for $\mathrm{CO}_{2}$-enhanced coalbed methane recovery. Int J Coal Geol 86:177-189. doi:10.1016/j.coal. 2011.01.004

Yang W, Lin BQ, Qu Y, Li ZW, Zhai C, Jia LL, Zhao WQ (2011) Stress evolution with time and space during mining of a coal seam. Int J Rock Mech Min Sci 48(7):1145-1152. doi:10.1016/j.ijrmms.2011.07.006

Zhang N, Zhang N, Han C, Qian D, Xue F (2013) Borehole stress monitoring analysis on advanced abutment pressure induced by Longwall Mining. Arab J Geosci 7(2):457-463. doi:10.1007/s12517-013-0831-7 